\title{
Aspectos do desenvolvimento e da efetividade do direito à educação no Brasil
}

\author{
Patrícia Ribeiro Vieira ${ }^{1}$
}

\section{Resumo}

O presente artigo visa relacionar aspectos da teoria do desenvolvimento como liberdade de Amartya Kumar Sen pertinentes à educação com a efetividade do princípio enunciado no art. 205 da Constituição Federal, que estabelece educação como direito de todos. A efetividade está relacionada à capacidade de atingir os fins para os quais a norma foi criada. Para medir a efetividade do art. 205 da CF/88, levantam-se dados sobre a trajetória do gasto público com educação, número de matrículas, erradicação do analfabetismo, nível de qualidade da Educação e acesso à educação superior, pois esses indicadores são fundamentais para medir o resultado na área da educação. Amartya Sen compreende a educação como um dos fatores que colaboram para o desenvolvimento de um país. A análise proposta viabiliza avaliar os avanços e os desafios que se colocam à frente do desenvolvimento do país em termos educacionais no pós-88. É possível apontar uma significativa melhora no quadro nacional devido à implementação de políticas públicas educacionais na última década.

Palavras-chave: Desenvolvimento. Educação. Políticas educacionais.

\section{Introdução}

O presente artigo visa relacionar aspectos da teoria do desenvolvimento como liberdade de Amartya Kumar Sen pertinentes à educação com a efetividade do princípio enunciado no art. 205 da Constituição Federal, que estabelece educação como direito de todos. Para tanto, o artigo está estruturado em duas partes: a primeira traz a exposição de aspectos da teoria de Sen que se relacionam

\footnotetext{
${ }^{1}$ Mestranda em Direito e Políticas Públicas pelo Centro Universitário de Brasília - UniCEUB.
} 
diretamente com a questão educacional, e a segunda traz a análise da efetividade do art. 205 da CF/88, a partir de dados estatísticos. ${ }^{2}$

A proposta de trazer à discussão a questão educacional brasileira fundamenta-se nos motivos amplamente conhecidos e que embasam processos educacionais seletivos e excludentes, quais sejam: o elevado índice de analfabetismo cujas raízes remontam à escravidão e à forma de colonização do país que também implicou em uma chegada tardia da educação superior no Brasil; em baixa qualidade de ensino; e em baixo rendimento dos estudantes e suas precárias condições socioeconômicas. ${ }^{3}$

A abordagem da teoria do "Desenvolvimento como liberdade" será direcionada para os pontos que interessam à questão educacional, ou seja, 1) a relação entre pobreza de rendas e pobreza de capacidades; e 2) a distinção entre capital humano e capacidade humana. Outros pontos da teoria de Amartya Sen serão trazidos para uma breve compreensão do desenvolvimento como liberdade, no entanto, a atenção está voltada para os dois pontos elegidos, pois se relacionam ao objeto deste estudo.

A segunda parte do trabalho analisa a possibilidade de se falar em efetividade do direito à educação, partindo do princípio da educação como direito de todos, art. 205 da CF/88, segundo o qual “a educação, direito de todos e dever do Estado e

2 Destaca-se que, para a análise do art. 205 da CF/88, utilizou-se de dados estatísticos já compilados pelo Instituto de Pesquisa Econômica Aplicada - IPEA, especificamente pela Diretoria de Estudos e Políticas Sociais - DISOC. "A Disoc dedica-se à realização de estudos e pesquisas sobre condições de vida da população brasileira, assim como ao acompanhamento e à avaliação de processos de formulação, implementação e avaliações de políticas sociais. As suas principais áreas de atuação englobam seguridade e previdência social; trabalho; saúde; assistência social e segurança alimentar; direitos humanos; justiça e cidadania; demografia; educação; desigualdades (de gênero e racial); pobreza; cultura; habitação; e segurança pública”. Disponível em:<http://www.ipea.gov.br/default.jsp >. Acesso em: 23 maio 2010.

3 INSTITUTO DE PESQUISA ECONÔMICA APLICADA. Brasil em desenvolvimento: estado, planejamento e políticas públicas. Brasília: IPEA, 2009. Disponível em: <http:// www.ipea.gov.br/portal/index.php?option=com_content\&view=article\&id=239\&Item $\mathrm{id}=6>$. Acesso em: 12 maio 2010. p. 617. 
da família, será promovida e incentivada com a colaboração da sociedade, visando ao pleno desenvolvimento da pessoa, seu preparo para o exercício da cidadania e sua qualificação para o trabalho."

Para tanto, é necessário compreender aspectos da estrutura educacional, o que passa pela análise de cinco perspectivas: 1) trajetória do gasto público; 2) número de matrículas; 3) a erradicação do analfabetismo; 4) o nível de qualidade da educação; e 5) o acesso à educação superior. Tais perspectivas foram eleitas para analisar a efetividade do direito à educação, pois, para falar em educação como direito de todos é preciso verificar sobre que realidade se lança o desafio educacional. Outro aspecto relevante é o desafio de universalizar a educação primária, um dos “Objetivos de Desenvolvimento do Milênio", conforme adiante será explicitado.

A partir disso, propõe-se verificar quais são os pontos que impedem a universalização do ensino, em outras palavras, os nós críticos da estrutura educacional, a fim de elucidar os aspectos que inviabilizam o acesso e permanência do alunado no sistema de ensino.

\section{Educação na perspectiva do desenvolvimento como liberdade}

A abordagem do conceito de desenvolvimento é feita com base na teoria de desenvolvimento como liberdade de Amartya Kumar Sen. Para estabelecer um diálogo com a efetividade do direito à educação no Brasil, serão abordados, essencialmente, dois pontos: (1) a relação entre pobreza de rendas e pobreza de capacidades; e (2) a distinção entre capital humano e capacidade humana. A compreensão dessas relações é importante tendo em vista que a educação é um pilar para o desenvolvimento de um país, segundo a teoria de Sen. Antes de entrar especificamente nesses pontos, vale destacar dois aspectos: a ideia de desenvolvimento e de liberdade para Sen.

Sen apresenta "um novo enfoque do desenvolvimento visto como expansão das liberdades substantivas centrados nos agentes sociais. Uma das proposições do autor é a necessidade de se pensar a pobreza a partir de uma abordagem 
relacional". ${ }^{4}$ A ideia de desenvolvimento relaciona-se ao "processo de expansão de liberdades reais que as pessoas desfrutam", ${ }^{5}$ assim o crescimento do Produto Nacional Bruto - PNB - é um meio importante para a realização desse objetivo, da mesma forma que a remoção das principais fontes de privação de liberdade. ${ }^{67} \mathrm{~A}$ possibilidade fática de realização das pessoas sofre influência das "oportunidades econômicas, liberdades políticas, poderes sociais e por condições habilitadoras, como boa saúde, educação básica, incentivo e aperfeiçoamento de iniciativas". Também existe uma influência dos exercícios das liberdades das pessoas sobre a configuração das disposições institucionais. A abordagem proposta centra-se nas liberdades como os fins e os meios primordiais do desenvolvimento. ${ }^{9}$

${ }^{4}$ MENEZES, Roberto Goulart; RIBEIRO, Cláudio Oliveira. Políticas públicas pobreza e desigualdade no Brasil: apontamentos a partir do enfoque analítico de Amartya Sen. Disponível em: <http://revistaseletronicas.pucrs.br/ojs/index.php/fass/article/view/ 3937/2974>. Acesso em: 26 maio 2010.

5 SEN, Amartya Kumar. Desenvolvimento como liberdade. São Paulo: Companhia das Letras, 2000. p. 17.

6 Pobreza e tirania, carência de oportunidades econômicas e destituição social sistemática, negligência dos serviços públicos e intolerância ou interferência excessiva de Estados repressivos. SEN, Amartya Kumar. Desenvolvimento como liberdade. São Paulo: Companhia das Letras, 2000. p. 18.

7 Destaca-se que "até o final da década de 1980, sempre que se tratava do desenvolvimento, era difícil não atrelá-lo quase que exclusivamente ao crescimento do PIB ou da renda per capita”. MENEZES, Roberto Goulart; RIBEIRO, Cláudio Oliveira. Políticas públicas pobreza e desigualdade no Brasil: apontamentos a partir do enfoque analítico de Amartya Sen. Disponível em: <http://revistaseletronicas.pucrs.br/ojs/index.php/fass/article/ view/3937/2974>. Acesso em: 26 maio 2010.

8 MENEZES, Roberto Goulart; RIBEIRO, Cláudio Oliveira. Políticas públicas pobreza e desigualdade no Brasil: apontamentos a partir do enfoque analítico de Amartya Sen. Disponível em: <http://revistaseletronicas.pucrs.br/ojs/index.php/fass/article/view/ 3937/2974>. Acesso em: 26 maio 2010. p. 19.

9 MENEZES, Roberto Goulart; RIBEIRO, Cláudio Oliveira. Políticas públicas pobreza e desigualdade no Brasil: apontamentos a partir do enfoque analítico de Amartya Sen. Disponível em: <http://revistaseletronicas.pucrs.br/ojs/index.php/fass/article/view/ 3937/2974>. Acesso em: 26 maio 2010. p. 25. 
A liberdade possui o papel constitutivo e o instrumental no desenvolvimento. $\mathrm{O}$ primeiro diz respeito ao fim do desenvolvimento, sendo que a avaliação do desenvolvimento da pessoa deve partir do processo de expansão de liberdades humanas, de forma a incluir a "eliminação da privação dessa pessoa". ${ }^{10} \mathrm{O}$ papel instrumental da liberdade diz respeito à inter-relação entre a expansão da liberdade em geral e desenvolvimento e os diferentes tipos de direitos, oportunidades e intitulamentos. São identificados cinco tipos distintos de liberdades instrumentais: 1) liberdades políticas; 2) facilidades econômicas; 3) oportunidades sociais; 4) garantias de transparência; e 5) segurança protetora.

Portanto, o desenvolvimento de um país não resulta apenas do crescimento do PNB, mas também da remoção das principais fontes de privação de liberdade. A educação é um bem que colabora para o desenvolvimento, devido à influência que exerce sobre a pobreza de rendas. A educação não deve ser vista apenas para o fim de formação de capital humano, ou seja, apenas para tornar um indivíduo um elemento, dentre outros, de produção.

Amartya Sen utiliza a teoria do capital humano ${ }^{11}$ como um elemento que enriquece a abordagem, o que ocorre devido ao destaque da importância do indivíduo em uma época em que há o direcionamento para investimentos em tecnologia, em outras palavras, quanto maior o investimento em capital humano maior a capacidade de expansão do mercado nesse setor dentro do país. Portanto, apesar de considerar importante a formação de capital humano no contexto de expansão

${ }^{10}$ MENEZES, Roberto Goulart; RIBEIRO, Cláudio Oliveira. Políticas públicas pobreza e desigualdade no Brasil: apontamentos a partir do enfoque analítico de Amartya Sen. Disponível em: <http://revistaseletronicas.pucrs.br/ojs/index.php/fass/article/view/3937/2974>. Acesso em: 26 maio 2010. p. 52.

${ }^{11}$ Sobre capital humano: "correndo o risco de simplificação excessiva, pode-se dizer que a literatura sobre capital humano tende a concentrar-se na atuação dos seres humanos para aumentar as possibilidades de produção". SEN, Amartya Kumar. Desenvolvimento como liberdade. São Paulo: Companhia das Letras, 2000. p. 332. 
econômica, o conceito de desenvolvimento que trabalha não está restrito apenas à expansão econômica. ${ }^{12}$

\subsection{Relação entre pobreza de rendas e pobreza de capacidades}

Amartya Sen entende que existe uma relação entre pobreza de renda e pobreza de capacidades, embora sejam duas perspectivas distintas. Renda é um meio importante para a obtenção de capacidades e o aumento de capacidades ${ }^{13}$ de uma pessoa tende a aumentar sua produtividade e renda. ${ }^{14}$ Dessa forma, a educação básica e saúde, apesar de relacionarem-se diretamente ao aumento de qualidade de vida, "também aumentam o potencial da pessoa auferir renda e assim livrar-se da pobreza medida pela renda", de forma que "quanto mais inclusivo for o alcance da educação básica e dos serviços de saúde, maior será a probabilidade de que mesmo os potencialmente pobres ${ }^{15}$ tenham uma chance maior de superar a penúria”. ${ }^{16}$

${ }^{12}$ É importante entender que a proposta trazida por Amartya Sen é marcada pela indeterminação que encerra sua proposta. Esse exercício também é feito quando analisa a utilidade da teoria do capital humano para fins de desenvolver capacidades, em outras palavras, considera tal teoria útil, mas não encerra a análise nela, a fim de destacar suas vantagens e desvantagens. Tal exercício de construção teórica é aplicado à sua própria teoria. Sobre indeterminação como fechamento da teoria ética de Sen, ver HERNÁNDEZ, Andes. La teoria ética de Amartya Sen. Bogotá: Siglo del Hombre Editores; Universidad de los Andes, 2006.

13 "Sen no define al desarrollo en base a la renta [...] sino por la capacidad que tienen las personas de transformar esa renta en aquello que ellas consideran necesario para llevar la vida que quieren llevar. El desarrollo se basa en la libertad justamente porque esta permite a los individuos aumentar las capacidades que les permitan vivir de la forma en que quieran vivir, los cual es, según Sen, el objetivo de alcanzar un mayor desarrollo." EDO, María. Amartya Sen y el desarrollo como libertad: la viabilidad de una alternativa a las estrategias de promoción del desarrollo. Argentina: Universidad Torcuato di Tella, 2002. p. 21.

${ }^{14}$ SEN, Amartya Kumar. Desenvolvimento como liberdade. São Paulo: Companhia das Letras, 2000. p. 112.

${ }^{15}$ Para fins de esclarecimento, com a expressão potencialmente pobres, Sen refere-se a indivíduos que não possuem uma situação favorável à formação de capacidades e aquisição de riquezas, ou seja, acumulam potencialmente a pobreza de rendas e de capacidades.

${ }^{16}$ SEN, Amartya Kumar. Desenvolvimento como liberdade. São Paulo: Companhia das Letras, 2000. p. 113. 
A fim de corroborar tal perspectiva, Sen cita um trabalho que realizou em co-autoria com Jean Drèze sobre as reformas econômicas ocorridas na Índia. Destaca-se o que denominou de "preparo social":

De fato, muitas economias asiáticas [...] lograram um êxito notável na difusão das oportunidades econômicas graças a uma base social que proporcionava sustentação adequada, como altos níveis de alfabetização e educação básica, bons serviços gerais de saúde, reformas agrárias concluídas etc. ${ }^{17}$

A região de Kerala é um exemplo de onde a redução de pobreza de renda foi mais rápida do que em qualquer outro Estado da Índia, apesar de ter sido prejudicada por uma desconfiança quanto à expansão econômica, de forma a adotar políticas anti-mercado, o que ocasionou índices sofríveis de crescimento econômico. Tal fato se deu, pois, "enquanto alguns Estados reduziram a pobreza de renda por meio de elevado crescimento econômico (Punjab é o exemplo mais notável), Kerala baseou-se em grande medida na expansão da educação básica, serviços de saúde e distribuição equitativa de terras para seu êxito na redução da miséria”." ${ }^{18}$

Apesar de existirem relações entre os dois tipos de pobreza apontados, parte-se da premissa de que "a redução da pobreza não pode, em si, ser a motivação suprema de políticas de combate à pobreza”, pois seria perigoso ver o problema "da perspectiva limitada da privação de renda e a partir daí justificar investimentos em educação, serviços de saúde etc. com o argumento de que são bons meios para atingir o fim da redução da pobreza de renda. Isso seria confundir os fins com os meios". ${ }^{19}$

Acontece que o aumento das capacidades humanas também tende a andar junto com a expansão das produtividades e do poder de auferir renda. Essa conexão estabelece um importante encadeamento indireto mediante o qual um aumento de capacidades ajuda direta e indiretamente a

\footnotetext{
${ }^{17} \mathrm{SEN}$, Amartya Kumar. Desenvolvimento como liberdade. São Paulo: Companhia das Letras, 2000. p. 113.

${ }^{18}$ SEN, Amartya Kumar. Desenvolvimento como liberdade. São Paulo: Companhia das Letras, 2000. p. 114.

${ }^{19}$ SEN, Amartya Kumar. Desenvolvimento como liberdade. São Paulo: Companhia das Letras, 2000. p. 114.
} 
enriquecer a vida humana e a tornar as privações humanas mais raras e menos pungentes. ${ }^{20} 21$

Ao tratar da relação entre expectativa de vida e PNB, Sen destaca que "a expectativa de vida não se eleva com o crescimento do PNB per capita, mas indicaria que a relação tende a funcionar particularmente por meio do dispêndio público com serviços de saúde e por meio do êxito na eliminação da pobreza. $\mathrm{O}$ principal impacto do crescimento econômico depende muito do modo como seus frutos são aproveitados". 22 O que se confirma quando se volta os olhos ao exemplo de Kerala. ${ }^{23}$

Dessa forma, podemos perceber a importância do investimento em educação por parte do Estado. A educação, uma vez que seus benefícios ultrapassam o ganho individual pode ser definida como bem semi-público ${ }^{24}$ por conter um componente de bem público, uma vez que "uma expansão geral da educação e

${ }^{20}$ SEN, Amartya Kumar. Desenvolvimento como liberdade. São Paulo: Companhia das Letras, 2000. p. 114.

${ }^{21}$ Em sua obra "Desenvolvimento como liberdade", Amartya Sen entende que o desenvolvimento - nesse momento abordado como crescimento econômico - tem de estar relacionado à melhoria de qualidade de vida e aumento das liberdades que são desfrutadas. A expansão das liberdades justifica-se por uma dupla finalidade: i) à medida que enriquece e retira impedimentos e ii) viabiliza a formação de seres sociais mais completos, que colocam em prática suas volições de forma a interagir e influenciar o mundo em que se vive. SEN, Amartya Kumar. Desenvolvimento como liberdade. São Paulo: Companhia das Letras, 2000. p. 29.

${ }^{22}$ SEN, Amartya Kumar. Desenvolvimento como liberdade. São Paulo: Companhia das Letras, 2000. p. 61.

${ }^{23}$ A tese defendida por Sen é a de que o desenvolvimento deve ser visto como um processo de expansão das liberdades reais que as pessoas desfrutam. Ela contrasta com visões mais restritas, como as que identificam desenvolvimento como crescimento do PIB, aumento de renda per capita, industrialização, avanço tecnológico ou modernização. Esses cinco elementos são obviamente importantíssimos como meios de expandir as liberdades. Mas as liberdades são essencialmente determinadas por saúde, educação e direitos civis. MENEZES, Roberto Goulart; RIBEIRO, Cláudio Oliveira. Políticas públicas pobreza e desigualdade no Brasil: apontamentos a partir do enfoque analítico de Amartya Sen. Disponível em: <http://revistaseletronicas.pucrs.br/ojs/index.php/fass/article/ view/3937/2974>. Acesso em: 26 maio 2010..

${ }^{24}$ Dados os benefícios da educação básica compartilhados pela comunidade, que podem transcender os ganhos da pessoa que está recebendo a educação, a educação básica pode conter também um componente de bem público (e pode ser vista como liberdade. São Paulo: Companhia das Letras, 2000. p. 154 
alfabetização em uma região pode favorecer a mudança social, ${ }^{25}[. .$.$] , além de aju-$ dar a aumentar o progresso econômico que beneficia também outras pessoas" ${ }^{26} \mathrm{O}$ papel do Estado é fundamental na expansão da educação básica de forma notável em todo o mundo. ${ }^{27}$

Nesse sentido, o gasto público com educação é um fator importante para a redução da pobreza de rendas por meio da redução da pobreza como capacidades, pois "com um gasto irrisório o governo pode facilitar, pode incentivar e pode até mesmo impor a quase todo o povo a necessidade de adquirir as partes mais essenciais da educação". ${ }^{28}$ Entretanto, a questão do gasto, apesar de importante, não é fator suficiente para pensar a educação como um pilar de desenvolvimento do país. A segunda parte do trabalho é dedicada a desenvolver essa consideração.

\subsection{Distinção entre capital humano e capacidade humana}

A perspectiva da inserção do indivíduo no desenvolvimento de um país é um ponto central da teoria do desenvolvimento como liberdade. Para tanto, faz-se necessária a distinção entre capital humano ${ }^{29}$ e capacidade humana. A perspectiva do capital humano atribui relevância à educação, na medida em que esta guarda relação com o aumento de produtividade humana que, por sua vez, colabora com

\footnotetext{
${ }^{25}$ Até mesmo a redução da fecundidade e da mortalidade

${ }^{26}$ MENEZES, Roberto Goulart; RIBEIRO, Cláudio Oliveira. Políticas públicas pobreza e desigualdade no Brasil: apontamentos a partir do enfoque analítico de Amartya Sen. Disponível em: <http://revistaseletronicas.pucrs.br/ojs/index.php/fass/article/ view/3937/2974>. Acesso em: 26 maio 2010. p. 154.

${ }^{27}$ A rápida disseminação da alfabetização na história dos países hoje ricos (no Ocidente, no Japão e no restante da Ásia) baseou-se no baixo custo da educação pública combinado a seus benefícios públicos compartilhados”. MENEZES, Roberto Goulart; RIBEIRO, Cláudio Oliveira. Políticas públicas pobreza e desigualdade no Brasil: apontamentos a partir do enfoque analítico de Amartya Sen. Disponível em: <http://revistaseletronicas. pucrs.br/ojs/index.php/fass/article/view/3937/2974>. Acesso em: 26 maio 2010. p. 154.

${ }^{28}$ SEN, Amartya Kumar. Desenvolvimento como liberdade. São Paulo: Companhia das Letras, 2000. p. 154.

${ }^{29}$ Destaca-se que a abordagem feita da teoria do capital humano aqui não é exaustiva, pois o objetivo é mostrar seu núcleo de proposição teórica.
} 
o processo de expansão econômica. ${ }^{30}$ Dessa forma, apesar do ser humano situar-se de forma central nessa teoria, o direcionamento oferecido reside na "atuação dos seres humanos para aumentar as possibilidades de produção". ${ }^{11}$ Por sua vez, a perspectiva da capacidade humana "concentra-se no potencial - liberdade substantiva - das pessoas para levar a vida que elas têm razão para valorizar e para melhorar as escolhas reais que elas possuem".32

Tendo em consideração as duas teorias, nota-se que a primeira situa a valorização do humano, antes, em sua contribuição para o aumento da produção ou obtenção de um melhor preço no mercado e, depois, no enriquecimento direto da vida do humano, por exemplo, tornando uma pessoa bem nutrida e sadia. Portanto, a valorização das qualidades humanas na teoria do capital humano é utilizada a título de capital na produção. ${ }^{33}$ "Nesse sentido, a visão mais restrita da abordagem do capital humano insere-se na perspectiva mais abrangente da capacidade humana, que pode abarcar as consequências tanto diretas como indiretas das qualificações humanas", ${ }^{34}$ ou seja, o fito de expansão de mercado e maior obtenção de renda é considerado na teoria da capacidade humana, de forma indireta e na medida em que colabora para a expansão de capacidades.

Portanto, no delineamento do desenvolvimento como liberdade, tem-se em conta o uso do conceito de capital humano como uma abordagem enriquecedora, que carece de suplementação, pois "seres humanos não são meramente meios de

\footnotetext{
30 " $\mathrm{Na}$ análise econômica contemporânea, a ênfase passou, em grande medida, de ver a acumulação de capital primordialmente em termos físicos a vê-la como um processo no qual a qualidade produtiva dos seres humanos tem uma participação integral". SEN, Amartya Kumar. Desenvolvimento como liberdade. São Paulo: Companhia das Letras, 2000. p. 331.

${ }^{31}$ SEN, Amartya Kumar. Desenvolvimento como liberdade. São Paulo: Companhia das Letras, 2000. p. 332.

32 SEN, Amartya Kumar. Desenvolvimento como liberdade. São Paulo: Companhia das Letras, 2000. p. 332.

${ }^{33}$ Segundo o autor: do modo como se emprega o capital físico.

${ }^{34}$ SEN, Amartya Kumar. Desenvolvimento como liberdade. São Paulo: Companhia das Letras, 2000. p. 332.
} 
produção, mas também a finalidade de todo o processo". ${ }^{35}{ }^{36}$ Sen critica a teoria do capital humano da seguinte forma:

O reconhecimento do papel das qualidades humanas na promoção e sustentação do crescimento econômico - ainda que importantíssimo - nada nos diz sobre a razão de se buscar o crescimento econômico antes de tudo. Se, em vez disso, o enfoque for, em última análise, sobre a expansão da liberdade humana para levar o tipo de vida que as pessoas com razão valorizam então o papel do crescimento econômico na expansão dessas oportunidades tem de estar integrado à concepção mais fundamental do processo de desenvolvimento como a expansão da capacidade humana para levar uma vida mais livre e mais digna de ser vivida. ${ }^{37}$

A perspectiva do capital humano seria apenas uma das abordagens pertinentes à perspectiva da capacidade humana, pois, uma compreensão mais integral das capacidades humanas orienta-se por três fundamentos: 1) sua relevância direta para o bem-estar e a liberdade das pessoas; 2) seu papel indireto, influenciando a mudança social; e 3 ) seu papel indireto, influenciando a produção econômica. ${ }^{38}$

\subsection{Considerações intermediárias}

Diante do exposto, vimos que a teoria de desenvolvimento como liberdade parte da premissa de que o crescimento econômico tem de estar relacionado à melhoria de qualidade de vida e ao aumento das liberdades que são desfrutadas, ${ }^{39}$

${ }^{35}$ SEN, Amartya Kumar. Desenvolvimento como liberdade. São Paulo: Companhia das Letras, 2000. p. 334.

${ }^{36}$ Sen destaca o posicionamento de Adam Smith: "[...] parece impossível que a aprovação da virtude deva ser do mesmo tipo daquela com que aprovamos uma edificação conveniente ou bem planejada, ou que não deveríamos ter outra razão para louvar um homem além daquela pela qual elogiamos uma cômoda" SEN, Amartya Kumar. Desenvolvimento como liberdade. São Paulo: Companhia das Letras, 2000. p. 335.

${ }^{37}$ SEN, Amartya Kumar. Desenvolvimento como liberdade. São Paulo: Companhia das Letras, 2000. p. 334.

${ }^{38}$ SEN, Amartya Kumar. Desenvolvimento como liberdade. São Paulo: Companhia das Letras, 2000. p. 335.

${ }^{39}$ SEN, Amartya Kumar. Desenvolvimento como liberdade. São Paulo: Companhia das Letras, 2000. p. 29. 
sendo que o papel do aumento das riquezas está estritamente vinculado ao aumento de liberdades; entretanto estas não podem ser vistas apartadas daquelas no direcionamento de políticas públicas. O exemplo claro é o da saúde e da educação, fatores sociais que colaboram para aumentar o nível de qualidade de vida e prepara a população para aproveitar o crescimento econômico. Dessa forma, a relação entre pobreza de rendas e pobreza de capacidades ocorre na medida em que "o aumento das capacidades humanas tende a andar junto com a expansão das produtividades e do poder de auferir renda". ${ }^{40}$ Destaca-se que a redução de pobreza de capacidades está relacionada de forma indireta à redução da pobreza de renda e de forma direta ao aumento da qualidade de vida.

Conforme a concepção de Amartya Sen, “a riqueza evidentemente não é o bem que estamos buscando, sendo ela meramente útil e em proveito de alguma outra coisa". ${ }^{41}$ A concepção de riqueza exposta no começo do livro torna nítida a distinção entre o desenvolvimento que tem por foco o crescimento do produto per capita e o que visa a uma concentração mais fundamental na expansão da liberdade humana. Esta se baseia na formação de capacidades, em outras palavras, na possibilidade de alcançar os que possuem razão para valorizar, sendo a liberdade de escolha o ponto para valorar a aquisição do nível de renda.

Quando Sen analisa a formação de capital humano, tece críticas à inserção do ser humano como, meramente, um meio de produção para o mercado de forma a deslocar o posicionamento do primeiro em relação ao segundo. Portanto, apesar de considerar de grande utilidade a perspectiva do capital humano, considera-a apenas como uma abordagem útil e não se restringe a ela.

Uma das principais contribuições das teorias de Amartya Sen, por meio dos indicadores de desenvolvimento humano, foi sua influencia na definição dos Objetivos de Desenvolvimento do Milênio - ODM, firmado no ano 2000 por 191 chefes

\footnotetext{
${ }^{40}$ SEN, Amartya Kumar. Desenvolvimento como liberdade. São Paulo: Companhia das Letras, 2000. p. 114.

${ }^{41}$ Aristóteles em Ética a Nicômaco: "The Nicomachean ethics, ed. rev. trad. D. Ross, Oxford University Press, 1980, livro I, seção 5, p. 7.” SEN, Amartya Kumar. Desenvolvimento como liberdade. São Paulo: Companhia das Letras, 2000. p. 28.
} 
de Estado. O documento dessa iniciativa estabeleceu metas para 2015 a partir da proposta de inserção dos direitos humanos sob a perspectiva do desenvolvimento. Para educação, foi estabelecida a meta de "garantir que até 2015 todas as crianças, meninos e meninas, concluam o nível primário de ensino". Essa meta se subdivide em meta 3, designada pelas Nações Unidas, e meta 3A, formulada pelo Brasil. Meta 3: "garantir que, até 2015, as crianças de todos os países, de ambos os sexos, terminem um ciclo completo de ensino". Meta 3A: "garantir que até 2015, todas as crianças, de todas as regiões do país, independentemente de cor/raça e sexo, concluam o ensino fundamental." ${ }^{42}{ }^{43}$ Como o presente estudo visa abordar a educação de forma sistêmica, a educação fundamental é um dos componentes a serem tratados.

Dessa forma, a partir dos aspectos explicitados da teoria de desenvolvimento como liberdade, pretende-se pousar a atenção sobre a análise aspectos da efetividade do direito à educação no Brasil, tendo em vista a importância da educação para o desenvolvimento de um país.

\section{Aspectos da efetividade do direito à educação no brasil}

O conceito de efetividade, aqui utilizado, está ligado à realização do objetivo proposto pela norma, de forma que "a norma é efetiva quando atinge os fins para os quais ela foi criada”. ${ }^{44}$ Há distinção entre eficácia e efetividade. Sendo a primeira, a capacidade de atingir resultados e a segunda, a realização desses resultados. A efetividade de uma norma está sujeita à gradação "conforme tenha, de fato, alcançado os objetivos pretendidos, de forma mais ou menos positiva". 45

${ }^{42}$ INSTITUTO DE PESQUISA ECONÔMICA APLICADA. Objetivos de desenvolvimento do milênio. Relatório Nacional de acompanhamento. IPEA: Brasília, 2010. Disponível em: <http://www.ipea. gov.br>. Acesso em: 11 maio 2010

${ }^{43}$ Destaca-se que tal perspectiva de igualdade assemelha-se ao conceito de igualdade complexa, citada por Maria Del Carmen Feijóo, ao tratar da insuficiência do modelo igualitário sarmientista na Argentina. FEIJOÓ, Maria del Carmen. Argentina: equidad social y eduación en los '90. Buenos Aires: IIPE -UNESCO, 2002. p. 16

${ }^{44}$ BARROS-PLAUTIAU, Ana Flávia; VARELLA, Marcelo Dias. A efetividade do direito internacional ambiental. Brasília: UniCEUB ; UNITAR ; UnB, 2009. p. 32.

${ }^{45}$ BARROS-PLAUTIAU, Ana Flávia; VARELLA, Marcelo Dias. A efetividade do direito internacional ambiental. Brasília: UniCEUB ; UNITAR ; UnB, 2009. p. 32. 
Propõe-se trazer algumas contribuições para analisar a efetividade ${ }^{46} \mathrm{da}$ educação como direito de todos no Brasil. Para tanto, inicialmente parte-se de estudo realizado pelo IPEA ${ }^{47}$, "Brasil em desenvolvimento. Estado, Planejamento e Políticas Públicas", que, dentre uma diversidade de temas, tratou da questão da "efetivação do direito à educação: inclusão e melhoria de qualidade", ${ }^{48}$ e, partindo do princípio da educação como direito de todos, analisaram-se três perspectivas: 1) a erradicação do analfabetismo; 2) o nível de qualidade da Educação; e 3) o acesso à educação superior. Tal recorte foi fundamentado nas seis prováveis condicionantes da defasagem da educação no Brasil:

A começar pelo elevado índice de analfabetismo, cujas raízes remontam à escravidão e ao pouco interesse que o colonizador português conferiu à educação na colônia. Este desinteresse também implicou na chegada tardia da educação superior ao Brasil, muito tempo depois de sua implantação em diversas colônias da América hispânica. A baixa qualidade do ensino ofertado e o incipiente rendimento dos estudantes da maioria das escolas públicas brasileiras também resultam de modelo de expansão dos sistemas de ensino órfão dos necessários aportes de recursos. Além de o financiamento ser insuficiente, o que compromete em grande medida a qualidade do ensino ofertado pelos sistemas públicos, as precárias condições socioeconômicas de parcela considerável do alunado tendem a agravar seu rendimento escolar. Como decorrência de tais fatores, os processos educacionais tornam-se seletivos e excludentes, de modo que boa parte do alunado é submetida a sucessivas reprovações que, no limite, culminam com a evasão escolar definitiva. ${ }^{49}$

${ }^{46}$ Parte-se do conceito de efetividade descrito acima, sem pretensão de discutir o próprio conceito, pois não é objeto deste estudo.

${ }^{47}$ Fundação pública vinculada à Secretaria de Assuntos Estratégicos, o IPEA fornece suporte técnico e institucional às ações governamentais - possibilitando a formulação de inúmeras políticas públicas e de programas de desenvolvimento brasileiro - e disponibiliza, para a sociedade, pesquisas e estudos realizados por seus técnicos. INSTITUTO DE PESQUISA ECONÔMICA APLICADA. Brasil em desenvolvimento: estado, planejamento e políticas públicas. Brasília: IPEA, 2009. Disponível em: <http://www.ipea.gov.br/portal/index. php? option=com_content\&view=article\&id=239\&Itemid=6>. Acesso em: 12 maio 2010.

${ }^{48}$ INSTITUTO DE PESQUISA ECONÔMICA APLICADA. Brasil em desenvolvimento: Estado, planejamento e políticas públicas. Brasília: IPEA, 2009. Capítulo 22 do $3^{0}$ volume.

${ }^{49}$ INSTITUTO DE PESQUISA ECONÔMICA APLICADA. Brasil em desenvolvimento: Estado, planejamento e políticas públicas. Brasília: IPEA, 2009. p. 617. 
A proposta do IPEA foi abordar a educação de uma forma sistêmica, localizando os nós críticos e demandando a articulação entre os entes da federação e sociedade. Para tanto, valeu-se do Plano de Desenvolvimento da Educação - PDE - lançado em 2007 pelo MEC. ${ }^{50}$ O PDE é um conjunto de ações ordenadas em torno da concepção sistêmica de educação. ${ }^{51}$ A ideia é a criação de "círculos virtuosos de efeitos multiplicadores em cada nível e/ou modalidade de ensino para com os demais, de modo a ampliarem-se as oportunidades de acesso e de qualidade da educação ofertada aos brasileiros". 5253

Além dos aspectos priorizados pelo IPEA no estudo citado, elegeram-se outros dois que permitem o alargamento da abordagem da questão educacional no Brasil, quais sejam, a trajetória dos gastos públicos e a trajetória das matrículas ${ }^{54}$ no período de 1995 a 2005, tendo em vista que o próprio objetivo do PDE relaciona-se ao acesso e à qualidade. Dados indicam que o Brasil tem um alto gasto com a Educação, cerca de 5,5\% do seu PIB, que se aproxima da média mundial e de países que são bem sucedidos na área educacional, entretanto, trata-se de um mal gasto ${ }^{55}$, tendo em vista o baixo nível de qualidade da educação. ${ }^{56}$

${ }^{50}$ Sobre o PDE uma síntese de sua proposta de implantação pode ser vista em: INSTITUTO DE PESQUISA ECONÔMICA APLICADA. Políticas sociais: acompanhamento e análise: 20 anos da Constituição Federal. 17. ed. Brasília: IPEA, 2009. v. 2. Como também em: HADDAD, Fernando. O plano de desenvolvimento da educação: razões, princípios e programas. Brasília: Inep, 2008.

${ }^{51}$ INSTITUTO DE PESQUISA ECONÔMICA APLICADA. Brasil em desenvolvimento: estado, planejamento e políticas públicas. Brasília: IPEA, 2009. p. 618.

${ }^{52}$ INSTITUTO DE PESQUISA ECONÔMICA APLICADA. Brasil em desenvolvimento: estado, planejamento e políticas públicas. Brasília: IPEA, 2009. p. 619.

${ }^{53}$ A ideia de círculo/ciclo também está presente em CASTRO, Cláudio de Moura. Educação brasileira: consertos e remendos. Rio de Janeiro: Rocco, 2007. p. 51: "Quem vai continuar a educar a nossa juventude é a escola que aí está com os seus professores e sua administração”.

${ }^{54}$ Destaca-se que os dados utilizados são, em sua maioria, os tratados pelo IPEA em distintas publicações.

${ }^{55}$ Há quem considere que "má administração" seria uma expressão mais adequada. Entretanto, para fins deste trabalho será mantida a concepção de Cláudio de Moura Castro.

${ }^{56}$ CASTRO, Cláudio de Moura. Educação brasileira: consertos e remendos. Rio de Janeiro: Rocco, 2007. p. 30. 
Portanto, para a compreensão dos pontos de análise do estudo sobre efetividade da educação no Brasil, é preciso ter em mente a estrutura sobre a qual os desafios são lançados, dentro de uma análise mais ampla. Em outras palavras, a abordagem sistêmica abarcará a questão do gasto com a educação, das matrículas ${ }^{57}$ no período de 1995 a 2005, e em seguida, a questão do analfabetismo, da qualidade educacional e do acesso à educação superior, com ênfase no período de 2004 a 2007.58 Também será feita a abordagem do Relatório Nacional de Acompanhamento dos ODM de 2010, que traz dados referentes aos anos de $1992,{ }^{59} 2005$ e 2008 que trata do desafio de universalizar a educação primária.

\subsection{Trajetória dos gastos com educação}

A análise da trajetória dos gastos com educação, bem como a análise posterior, sobre a trajetória do número de matrículas revelam os principais avanços em termos educacionais nos últimos anos. São dois aspectos que se relacionam ao princípio da educação como um direito de todos, previsto no art. 205 da Constituição Federal.

A trajetória dos gastos com educação demonstra o processo de descentralização, que ganhou força após a Constituição de 1988, uma vez que estabeleceu um direcionamento claro para a municipalização das políticas públicas e sociais, "estipulando por sua vez, garantia de recursos e regimes de colaboração entre as esferas de governo para a consecução das novas incumbências". ${ }^{60}$ Tal aspecto é evidente quando se volta atenção para a configuração dos gastos segundo a esfera de governo, entretanto, não compõe o objeto deste artigo, que visa analisar em linhas gerais a progressão dos gastos educacionais.

${ }^{57}$ Esses dois elementos de análise demonstram a estrutura ampla do sistema educativo.

${ }^{58}$ Apesar de nesses três elementos haver a menção de suas trajetórias nos períodos anteriores, a ênfase é dada ao período de 2004-2007.

${ }^{59}$ A análise desse ano ficará um pouco restrita, como se verá adiante, tendo em vista a disponibilidade de dados.

${ }^{60}$ CASTRO, Jorge Abrahão de; DUARTE, Bruno de Carvalho. Descentralização da educação pública no Brasil: trajetória dos gastos e das matrículas. Brasília: IPEA, 2008. (Texto para Discussão, n. 1352). p. 7. 
No período de 1995 a 2005, houve um crescimento real dos gastos em $42 \%{ }^{61}$ realizado pelas três esferas do governo, o que corresponde a um crescimento anual de $3,5 \%$. Contudo, tal crescimento não se deu de forma constante: ${ }^{62}$

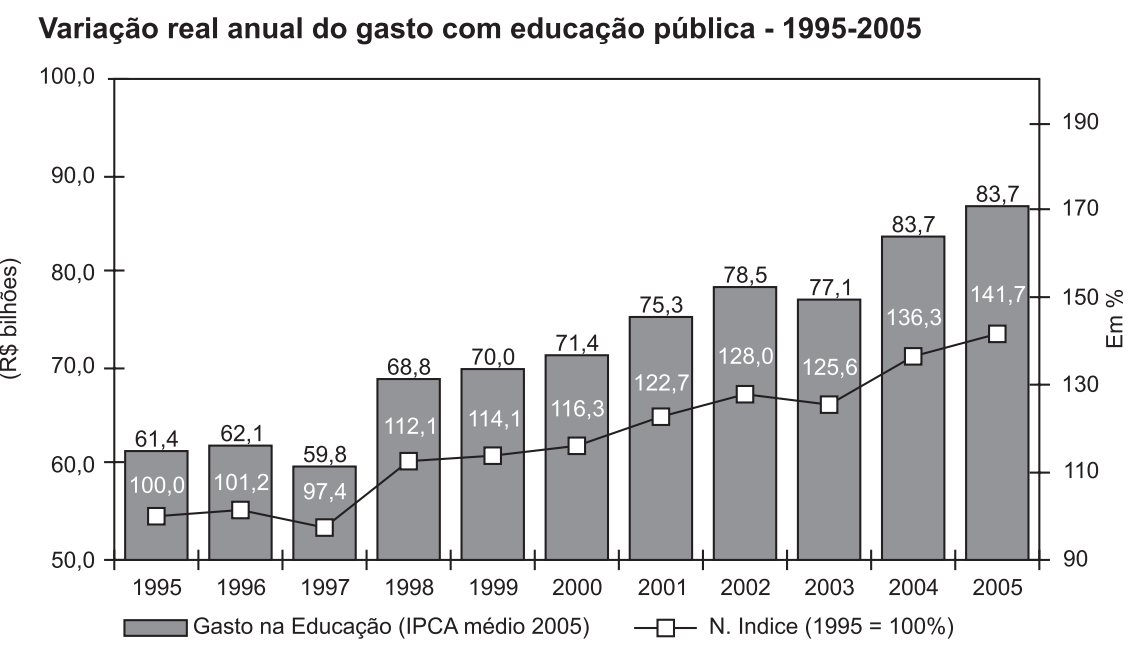

Fontes: Disoc/lpea, MP/IBGE, Slaf/STN, Inep/MEC e Almeida (2001).

Elaboração dos autores

Percebe-se que entre 1996 e 1997 houve o decréscimo de 3,8\%, recuperado no ano seguinte, em que houve o crescimento de 12,1\% em relação a 1995 e 14,7\% em relação a 1997. Salto de crescimento relativo comparável somente ao de 2004, $10,7 \%$, em relação a 2003, neste se constatou uma queda relativa a 2002 de 2,4\%. A ampliação real do gasto total foi de 25,6 bilhões, ou seja, saiu de 61,3 para $86,9 .{ }^{63}$

${ }^{61} \mathrm{O}$ estudo, fonte dos dados, indica que foram utilizados valores corrigidos, pois "permite uma noção da evolução do gasto descontando-se os valores que representam apenas a correção e a manutenção do poder de compra”. CASTRO, Jorge Abrahão de; DUARTE, Bruno de Carvalho. Descentralização da educação pública no Brasil: trajetória dos gastos e das matrículas. Brasília: IPEA, 2008. (Texto para Discussão, n. 1352). p. 19.

${ }^{62}$ CASTRO, Jorge Abrahão de; DUARTE, Bruno de Carvalho. Descentralização da educação pública no Brasil: trajetória dos gastos e das matrículas. Brasília: IPEA, 2008. (Texto para Discussão, n. 1352). p. 20.

${ }^{63}$ CASTRO, Jorge Abrahão de; DUARTE, Bruno de Carvalho. Descentralização da educação pública no Brasil: trajetória dos gastos e das matrículas. Brasília: IPEA, 2008. (Texto para Discussão, n. 1352). p. 20. 
Enquanto o aumento de gastos de 1995 a 2000 foi de 16,3\%, houve um crescimento de $21,8 \%$ de 2000 a 2005, ano em que foram firmados os "Objetivos de Desenvolvimento do Milênio" (ODM).

Existe uma disparidade na trajetória da distribuição de gastos entre as modalidades de ensino, que se relaciona à "configuração política e institucional que se molda em cada subárea - ela depende da luta política travada no interior do sistema educacional e dos embates com o setor econômico, e define os limites e as opções de ação governamental”. ${ }^{64}$

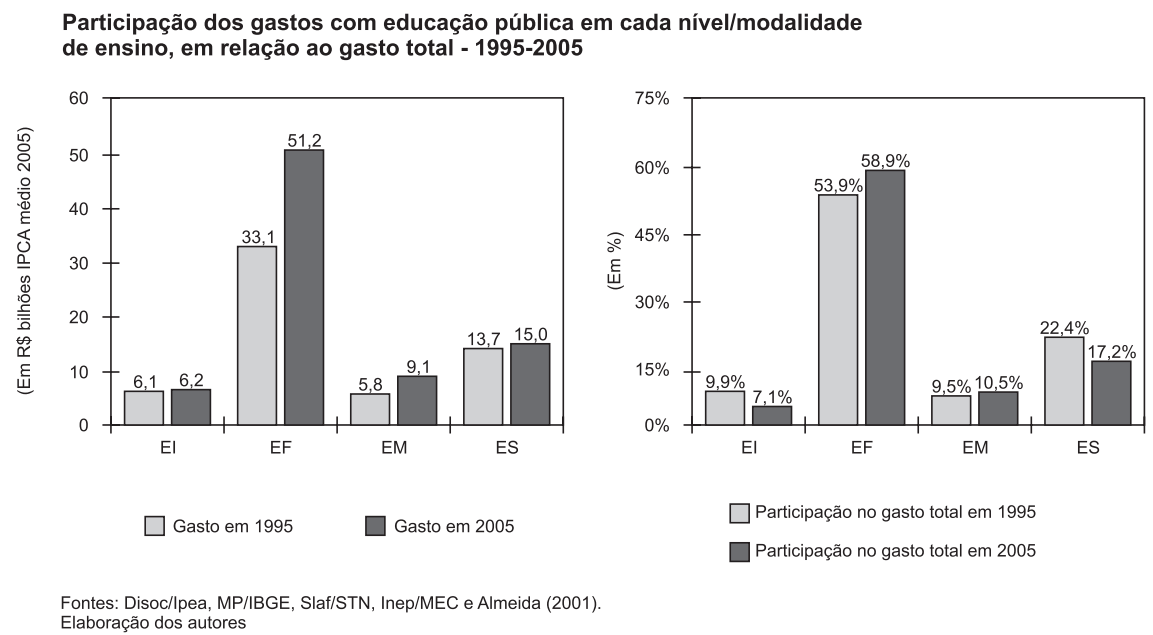

$\mathrm{O}$ gráfic ${ }^{65}$ revela que em todas as modalidades de ensino houve o aumento de gastos, sendo este mais sensível no EF, posteriormente, no EM seguido do ES e EI. O fato de ser sensível o aumento de gastos na área da educação, devido à alteração de normas referentes ao manejo político de tal área, demonstra a preocupação

\footnotetext{
${ }^{64}$ CASTRO, Jorge Abrahão de; DUARTE, Bruno de Carvalho. Descentralização da educação pública no Brasil: trajetória dos gastos e das matrículas. Brasília: IPEA, 2008. (Texto para Discussão, n. 1352). p. 20.

${ }^{65}$ CASTRO, Jorge Abrahão de; DUARTE, Bruno de Carvalho. Descentralização da educação pública no Brasil: trajetória dos gastos e das matrículas. Brasília: IPEA, 2008. (Texto para Discussão, n. 1352).p. 21.
} 
em direcionar investimentos para essa área, o que é um passo para o aprimoramento da estrutura educacional brasileira, pois de nada adiantaria concepções e planos bem articulados sem o devido aporte de recursos. ${ }^{66}$

\subsection{Trajetória das taxas de matrícula}

A trajetória dos números de matrículas permite visualizar, além do crescimento total das matrículas, a sua variação conforme a modalidade de ensino. Dessa forma, pode-se visualizar a ampliação da estrutura educacional conforme o nível de ensino, quais foram os avanços e quais são os limites dessa expansão. Em relação ao crescimento total das matrículas, pode-se observar seu comportamento por meio do gráfico a seguir: ${ }^{67}$

\section{Evolução da matrícula total de educação pública - 1995-2005}

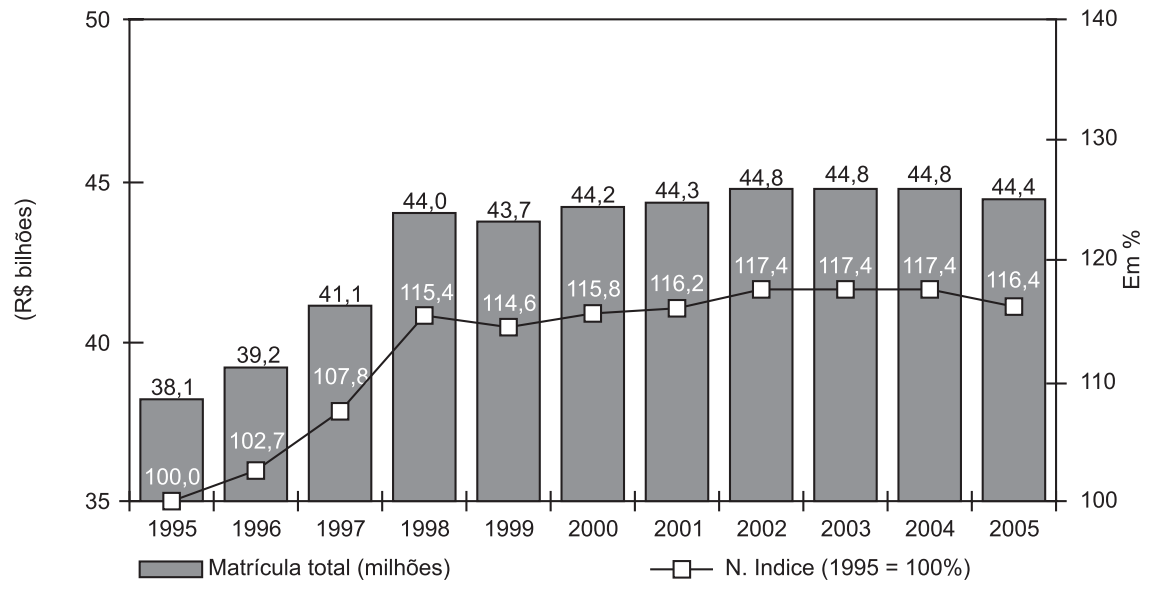

Fontes: Disoc/lpea, MP/IBGE, Inep/MEC

Elaboração dos autores

${ }^{66}$ Do total de gastos indicadores no gráfico anterior, 25,6 bilhões, 22,8 bilhões foram apresentados neste último gráfico.

${ }^{67}$ CASTRO, Jorge Abrahão de; DUARTE, Bruno de Carvalho. Descentralização da educação pública no Brasil: trajetória dos gastos e das matrículas. Brasília: IPEA, 2008. (Texto para Discussão, n. 1352). p. 26. 
O número total de matrículas em 1995 era de 38, 148 milhões, passando para 44,416 em 2005, o que revela um crescimento de $16,4 \%$. De 2000 a 2005, o crescimento foi de 0,2 milhões de matrículas. Destaca-se a estabilidade do número de matrículas na casa dos 44 milhões a partir de 1998 e o período de 2002 a 2004, que registrou o ápice do número de matrículas do período total com pequenas variações, em 2002, 44,767 milhões, em 2003, 44,803 milhões e em 2004, 44,789 milhões. Quanto à distribuição do número de matrículas de acordo com as modalidades de ensino:

\section{Participação da matrícula na educação pública por níveis/modalidades de ensino em relação à matrícula total - 1995-2005}
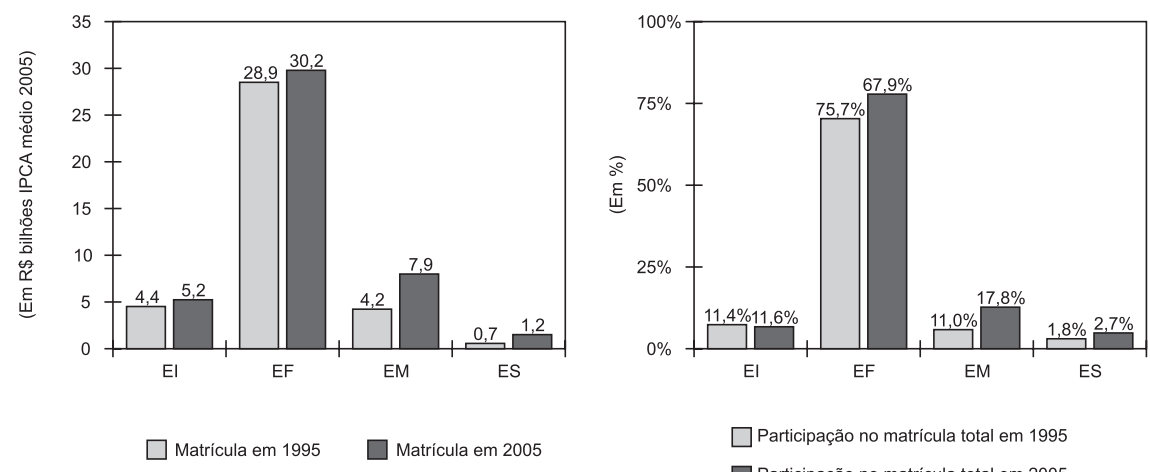

Legenda: EI - Educação Infantil; EF - Ensino Fundamental; EM - Ensino Médio; ES - Ensino Superior.

Fontes: Disoc/lpea, MP/IBGE, Inep/MEC.

Elaboração dos autores

Houve aumento do número absoluto e relativo de matrículas em todas as etapas de ensino, entretanto, o EF, não obstante estar sob foco de política pública específica, passou a representar uma parcela menor dentre o total de matrículas. Assim, apesar de o EF ter crescido 1,3 milhão, em termos relativos sofreu o decréscimo de 7,8\%, pois no EM o número de matrículas ascendeu em 3,7 milhões, o que representou o avanço em 6,7\% em termos relativos. Isso se deu, principalmente, em razão do aumento de número de matrículas no ensino médio em termos absolutos e relativos. Sobre tal configuração, vale ressaltar: 
Devido ao arranjo do sistema de educação pública no período, observa-se que o núcleo da oferta de escola pública está localizado no ensino fundamental, seguido do ensino médio. Entretanto, com o passar dos anos, esse mesmo arranjo estimulou, ainda que indiretamente, a demanda por - e, conseqüentemente, a oferta de - níveis e modalidades de ensino mais elevados, em especial do ensino médio. Essa observação é confirmada pela constatação de queda na participação relativa da matrícula no ensino fundamental, enquanto cresceu a participação dos demais níveis de ensino. ${ }^{68}$

Pelos dados trazidos, verifica-se que o comportamento das trajetórias de gastos e matrículas não foi similar, "os gastos tiveram variações mais abruptas do que a matrícula e cresceram a uma taxa real média anual de 3,5\%, enquanto as matrículas cresceram a uma taxa média de 1,5\% a.a." ${ }^{69}$ Portanto, fica evidente que não houve, necessariamente, uma relação fixa entre gasto e número de matrículas.

O gráfico que representa a "Participação da matrícula na educação pública por níveis/modalidades de ensino em relação à matrícula total - 1995-2005” apresenta um comportamento diferente do gráfico anterior que representa a "Participação dos gastos com educação pública em cada nível/modalidade de ensino, em relação ao gasto total - 1995-2005”. No EI, as matrículas cresceram 0,2\% e os gastos -2,8\%; no EF, as matrículas decresceram 7,8\% e os gastos cresceram 5\%; no EM, o crescimento foi de $6,71 \%$ e de $1 \%$ e no ES, de $0,9 \%$ nas matrículas e $-5,2$ nos gastos. Em termos absolutos, o crescimento de 22,8 bilhões nos gastos se relaciona ao crescimento de 6,3 milhões de matrículas. ${ }^{70}$ Quanto ao total de gastos, 81,5

${ }^{68}$ CASTRO, Jorge Abrahão de; DUARTE, Bruno de Carvalho. Descentralização da educação pública no Brasil: trajetória dos gastos e das matrículas. Brasília: IPEA, 2008. (Texto para Discussão, n. 1352). p. 27.

${ }^{69}$ CASTRO, Jorge Abrahão de; DUARTE, Bruno de Carvalho. Descentralização da educação pública no Brasil: trajetória dos gastos e das matrículas. Brasília: IPEA, 2008. (Texto para Discussão, n. 1352). p. 27.

${ }^{70}$ Gasto médio de R $\$ 3.619,50$ por matrícula. 
bilhões $^{71}$ e de matrículas 44,5 milhões ${ }^{72}$, obteve-se a média de gastos de 1.831,50 por matrícula $(\mathrm{g} / \mathrm{m})$. Dessa forma, em 2005, o g/m no EI foi de 1.192,31; no EF, de 1695,36; no EM, de 1.151,89 e no de ES, de 12.500 .

Ademais, as variações ocorridas no período revelam certa instabilidade na estrutura educacional brasileira em relação ao aporte de recursos, mas por outro lado, demonstra que tal instabilidade ${ }^{73}$ não afetou de forma significativa o número de matrículas nas respectivas modalidades de ensino. A combinação de tais comportamentos pode ter uma série de implicações internas à estrutura de ensino, entretanto, este estudo se limita a indicar tal possibilidade, sem entrar na análise micro das consequências das oscilações apontadas.

Após apontar quais foram os principais avanços na estrutura educacional brasileira, cabe introduzir os dados do Relatório Nacional de Acompanhamento dos "Objetivos de Desenvolvimento do Milênio" - ODM, realizado em março de 2010 pelo IPEA. O propósito de introduzir o resultado desse relatório e posteriormente os dados relativos ao analfabetismo, qualidade educacional e acesso à educação superior é de evidenciar alguns nós críticos da estrutura educacional.

\subsection{Relatório nacional de acompanhamento dos "objetivos de desenvolvimento do milênio" - ODM}

Este tópico propõe a abordagem do Relatório Nacional de Acompanhamento realizada em 2010, com dados referentes a 1992, 2005 e 2008. A meta estabeleci-

\footnotetext{
${ }^{71}$ Conforme soma dos valores do gráfico "Participação dos gastos com educação pública em cada nível/modalidade de ensino, em relação ao gasto total - 1995-2005”.

72 Aqui também se tomaram por base os dados do gráfico "Participação da matrícula na educação pública por níveis/modalidades de ensino em relação à matrícula total - 19952005, que apesar de demonstrar pequena distorção em relação aos dados do gráfico “Evolução da matrícula total da educação pública - 1995-2005”, 0,1 milhão, permite pensar os gastos proporcionalmente às matrículas.

${ }^{73}$ Não se pode afirmar que seja por completo instável em vista que apenas em um dos anos do período analisado houve o decréscimo de gastos em relação ao ano inicial do período, de forma que a instabilidade a que se refere está restrita a um faixa específica de gastos.
} 
da pelo Brasil foi de "garantir que até 2015, todas as crianças, de todas as regiões do país, independentemente de cor/raça e sexo, concluam o ensino fundamental." ${ }^{74} \mathrm{~A}$ aferição do cumprimento dessa meta é feita no Relatório de $2010^{75}$ pelos seguintes indicadores:

INDICADOR A: Taxa de frequência escolar líquida das pessoas de 7 a 17 anos, por grupos de idade e nível de ensino, segundo sexo e cor/raça - Brasil e grandes regiões.

INDICADOR B: Taxa de frequência líquida das pessoas de 7 a 17 anos de idade, segundo os quintos de rendimento familiar mensal per capita.

INDICADOR C: Proporção de pessoas de 11 e 12 anos que tenham concluído a $4^{\text {a }}$ série do ensino fundamental e pessoas de 18 anos que concluíram este nível de ensino.

INDICADOR D: Índice de adequação idade/anos de escolaridade, da população de 9 a 16 anos - Brasil e grandes regiões.

INDICADOR E: Taxa de alfabetização das pessoas de 15 a 24 anos de idade, segundo sexo, cor/raça e situação do domicílio - Brasil e grandes regiões. ${ }^{76}$

A partir dos resultados do primeiro indicador, foi possível constatar no âmbito do EF a diminuição das disparidades de acesso em todos os itens relacionados, portanto, foram reduzidas as desigualdades regionais; a desigualdade entre os se-

${ }^{74}$ INSTITUTO DE PESQUISA ECONÔMICA APLICADA. Objetivos de desenvolvimento do milênio. Relatório Nacional de acompanhamento. IPEA: Brasília, 2010. Disponível em: $<$ http://www.ipea. gov.br>. Acesso em: 11 maio 2010

${ }^{75}$ Destaca-se que o relatório de 2007 trazia sete indicadores, enquanto o de 2010 traz cinco. $\mathrm{O}$ indicador $\mathrm{C}$ tratava da "taxa média esperada e tempo médio de conclusão da $4^{\mathrm{a}}$ e da $8^{\text {a }}$ série do ensino fundamental”. O atual indicador E correspondia ao G, enquanto o indicador E tratava do "resultado do SAEB em língua portuguesa na $4^{\text {a }}$ série do ensino fundamental, por redes de ensino, em escolas urbanas", e o indicador F, dos "resultados do SAEB em matemática na $3^{\text {a }}$ série do ensino fundamental, por redes de ensino, em escolas urbanas". INSTITUTO DE PESQUISA ECONÔMICA APLICADA. Objetivos de desenvolvimento do milênio. Relatório Nacional de acompanhamento. IPEA: Brasília, 2010. Disponível em: <http://www.ipea. gov.br>. Acesso em: 11 maio 2010. A discussão sobre a mudança de indicadores não será objeto do presente artigo.

${ }^{76}$ INSTITUTO DE PESQUISA ECONÔMICA APLICADA. Objetivos de desenvolvimento do milênio. Relatório Nacional de acompanhamento. IPEA: Brasília, 2010. Disponível em: $<$ http://www.ipea. gov.br>. Acesso em: 11 maio 2010. p. 43 
xos foi anulada; as desigualdades de cor/raça foram sensivelmente atenuadas, bem como a de localização, rural/urbana. A seguir, a tabela com os dados: ${ }^{77}$

Taxa de escolarização líquida nas faixas etárias de 7 a 14 e de 15 a 17 anos, segundo sexo, cor/raça e localização Brasil e regiões, 1992*, 2005 e 2008

\begin{tabular}{|c|c|c|c|c|c|c|}
\hline \multirow{2}{*}{ Características Selecionadas } & \multicolumn{3}{|c|}{ Fundamental 7 a 14 anos } & \multicolumn{3}{|c|}{ Médio 15 a 17 anos } \\
\hline & 1992 & 2005 & 2008 & 1992 & 2005 & 2008 \\
\hline Total & 81,4 & 94,4 & 94,9 & 18,2 & 45,3 & 50,4 \\
\hline Norte & 82,5 & 93,1 & 93,6 & 11,7 & 30,7 & 39,7 \\
\hline Nordeste & 69,7 & 92,4 & 94,3 & 9,5 & 30,1 & 36,4 \\
\hline Sudeste & 88,0 & 95,8 & 95,7 & 24,3 & 57,4 & 61,9 \\
\hline Sul & 86,9 & 95,9 & 95,2 & 23,1 & 53,6 & 56,4 \\
\hline \multicolumn{7}{|l|}{ Sexo } \\
\hline Masculino & 79,9 & 94,1 & 94,9 & 15,1 & 40,6 & 44,4 \\
\hline Feminino & 82,7 & 94,7 & 94,9 & 21,3 & 50,1 & 56,8 \\
\hline \multicolumn{7}{|l|}{ Cor/Raça } \\
\hline Branca & 87,5 & 95,4 & 95,4 & 27,1 & 56,6 & 61,0 \\
\hline Preta e Parda & 75,3 & 93,6 & 94,7 & 9,2 & 35,6 & 42,2 \\
\hline \multicolumn{7}{|l|}{ Localização } \\
\hline Rural & 66,5 & 92,3 & 94,3 & 5,3 & 24,7 & 33,3 \\
\hline Urbana & 86,2 & 95,0 & 95,1 & 22,3 & 50,4 & 54,3 \\
\hline
\end{tabular}

Exclusive a população rural dos estados de RO, AC, AM, RR, PA e AP.

Fonte: IBGE. Pesquisa Nacional por amostra de Domicílios, PNDA; elaborado por Inep/ DTDIE.

A análise dos dados revela que houve o aumento em $87,5 \%$ dos números sintetizados no ano de 2008, ou seja, vinte e um de vinte e quatro. A diminuição da taxa de escolarização na faixa etária de 7 a 14 anos na Região Sudeste, Sul e Centro-oeste acabou colaborando para uma maior homogeneidade entre as regiões, de forma que a região mais escolarizada voltou a ser a Sudeste, pois esta sofreu queda de apenas 0,1 p.p. de 2005 a 2008, enquanto a sul sofreu a queda de 0,7 p. p. no mesmo período. A redução das disparidades ocorreu também devido ao crescimento

\footnotetext{
${ }^{77}$ INSTITUTO DE PESQUISA ECONÔMICA APLICADA. Objetivos de desenvolvimento do milênio. Relatório Nacional de acompanhamento. IPEA: Brasília, 2010. Disponível em: $<$ http://www.ipea. gov.br>. Acesso em: 11 maio 2010. p. 44.
} 
da taxa de forma mais acentuada na Região Norte e Nordeste, nesta principalmente. Dessa forma, a média nacional, que em 1992 situava-se em 81,4 e que sua formulação era composta de números díspares na ordem de 18,3 p.p. em 2008 passou a ser de $94,9^{78}$ com uma disparidade reduzida a 2,1 p. p. Em relação à taxa de escolarização na faixa etária de 15 a 17 anos, os números também são positivos. A média nacional passou de 18,2 para 50,4, o que corresponde a um acréscimo de $175 \%$.

Quanto à desigualdade entre o sexo feminino e masculino na faixa etária de 7 a 14 anos, que em 1992 era de 2,1 p. p. a favor do sexo feminino, em 2008 foi anulada, enquanto na faixa etária de 15 a 17 anos, passou de 6,2 para 14,4 p. p. no mesmo período em detrimento do sexo masculino. Este teve o crescimento de $194 \%$, enquanto a taxa de escolarização feminina teve o crescimento de $166 \%$, o que potencializou as desigualdades, pois para que se igualassem, a taxa de escolarização do sexo masculino teria de ter crescido $276 \%$ no período analisado.

Em relação à desigualdade entre cor/raça, observa-se que esta sofreu redução tanto no Ensino Médio - EM - quanto no EF. Neste, a redução foi de 11,5 p.p. enquanto naquele foi de -0,9 p.p., de forma que, a desigualdade no EF ficou na ordem de 0,7 p.p. enquanto no EM, 18,8 p.p. Tal movimento no ensino médio ocorreu, pois a taxa de escolarização dos brancos com idade entre 15 e 17 passou de 27,1\% em 1992 para 61\% em 2008, enquanto a dos pardos/negros foi a 9,2\% para $42,2 \%$, em outras palavras, enquanto a escolarização dos brancos cresceu $125 \%$, a dos pardos/negros cresceu $358,7 \%$, enquanto teria de crescer $563 \%$ no período de 1992 a 2005 para que a desigualdade fosse igual a zero.

Quanto à localização, no período compreendido entre 1992 e 2008, a desigualdade em torno da taxa de escolarização do EF passou de 19,7 p.p. para 0,8 p.p. enquanto no EM foi de 4 p.p. Entretanto, destaca-se que em 2005, no EF a desigualdade estava na ordem de 2,7 p.p. enquanto no EM estava na ordem de 25,7 p.p ou seja, no EM houve uma forte acentuação das desigualdades, conforme os dados de 2005, e ainda não foi recuperado o nível de desigualdade registrado em 1992, apesar de já demonstrar queda.

\footnotetext{
${ }^{78}$ Acréscimo de $12 \%$.
} 
Dessa forma, observa-se que as desigualdades já atenuadas no EF persistem no EM. Dos fatores que colaboraram para essa situação, destacam-se a disparidade da situação inicial do EM em relação ao EF e a vigência do Fundef, política pública específica para o $\mathrm{EF}^{79}$

Os resultados relativos ao indicador $\mathrm{B}$, taxa de frequência líquida das pessoas de 7 a 17 anos de idade, segundo os quintos de rendimento familiar mensal per capita, pode ser visualizado no seguinte gráfico: ${ }^{80}$

\section{Taxa de escolarização líquida na faixa etária de 7 a 14 anos, segundo os quintos de rendimentoa domiciliar per capita Brasil, 2005 e 2008}

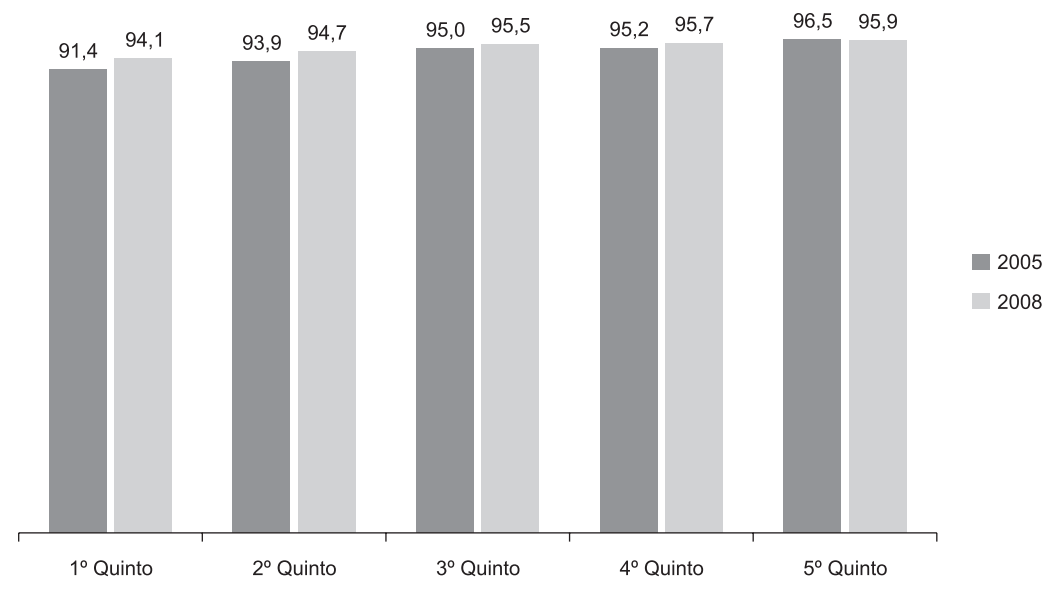

Fontes: IBGE, Pesquisa Nacional por Amostra de Domicílios, PNAD; elaborado por Inep/DTDIE.

A partir dos dados representados no gráfico acima, pode ser percebida uma tendência de equiparação entre os quintos de renda, de forma que a taxa de escola-

\footnotetext{
${ }^{79}$ Dada a vigência do FUNDEB, política pública direcionada para o ensino obrigatório - EF e EM - a expectativa é de que nos próximos anos essa desigualdade seja atenuada.

${ }^{80}$ INSTITUTO DE PESQUISA ECONÔMICA APLICADA. Objetivos de desenvolvimento do milênio. Relatório Nacional de acompanhamento. IPEA: Brasília, 2010. Disponível em: <http://www.ipea. gov.br>. Acesso em: 11 maio 2010. p. 45.
} 
rização entre o $1^{\circ}$ quinto e o $5^{\circ}$ quinto, passou de 5,1 p.p. para 1,8 p.p. ou seja, uma redução de $64,7 \% .{ }^{81}$ Tal diferença passa a ser expressiva quando analisado o EM, conforme gráfico a seguir: ${ }^{82}$

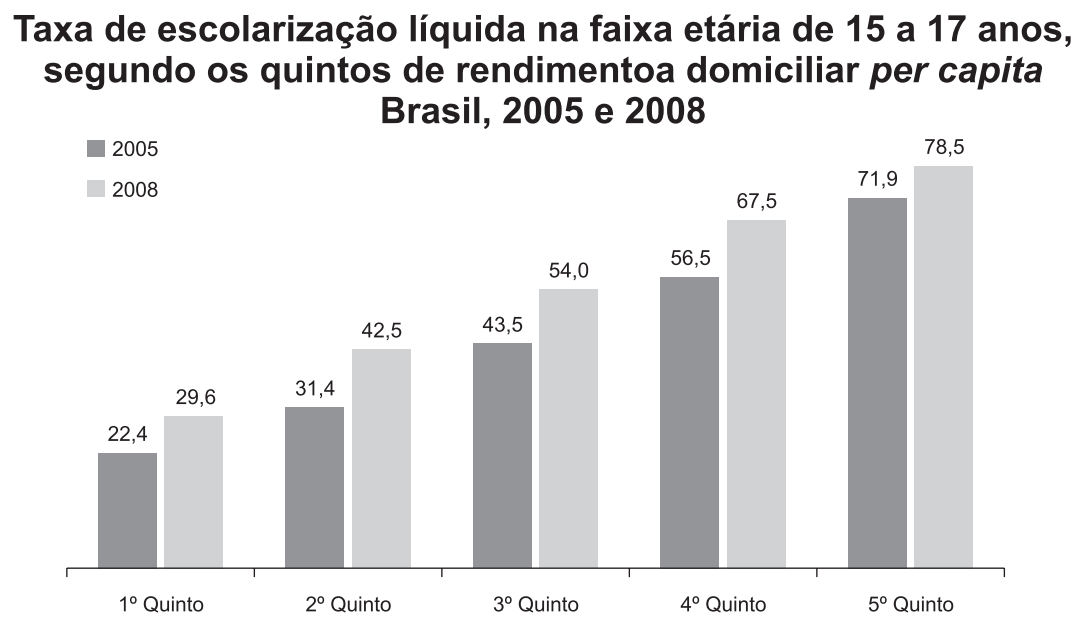

Fontes: IBGE, Pesquisa Nacional por Amostra de Domicilios, PNAD; elaborado por Inep/DTDIE.

Conforme os dados desse gráfico, observa-se que a disparidade entre os $20 \%$ mais pobres e o último extrato de renda era de 49,5 p.p. em 2005 e passou a ser de 48,9 p.p uma redução de 0,6 p.p. O crescimento da taxa de frequência no primeiro quinto foi de $32,1 \%$ e do último foi de $9,2 \%$, de forma que a equiparação de tal taxa entre as faixas de renda demandaria um crescimento na ordem de $250,4 \%$ entre 2005 e 2008 , tendo em vista que o crescimento de $1 \%$ no último quinto correspondeu a 0,719 p.p. e o primeiro quinto a 0,224 p.p; assim cada $1 \%$ de crescimento em cada quinto guardou a diferença de 0,495 p.p

${ }^{81}$ Base de cálculo: se 5,1 p. p. corresponde a 100\% da desigualdade existente em 2005, 1,8 p. p. corresponde a $35,3 \%$ dessa desigualdade, dessa forma, houve a redução de $64,7 \%$.

${ }^{82}$ INSTITUTO DE PESQUISA ECONÔMICA APLICADA. Objetivos de desenvolvimento do milênio. Relatório Nacional de acompanhamento. IPEA: Brasília, 2010. Disponível em: <http://www.ipea. gov.br>. Acesso em: 11 maio 2010. p. 46. 
É inequívoca a correlação entre renda e frequência ao ensinomédio. Pelo fato da distorção idade-série ser maior entre os estudantes de baixa renda, parcela considerável destes conclui o ensino fundamental na idade adulta, o que dificulta o ingresso e a permanência no ensino médio, tendo em vista sua necessidade de ingressar no mercado de trabalho. ${ }^{83}$

Ademais, esses números guardam a distorção idade/anos de escolaridade que "fica evidenciada quando se constata que $84 \%$ dos jovens de 15 a 17 anos frequentavam a escola em 2008, mas apenas 50\% cursavam o ensino médio. Entre os pertencentes ao primeiro quinto de renda, a taxa de frequência líquida mantinha-se quase 21 p. p. abaixo da média nacional". ${ }^{84}$ Para tratar da distorção idade/anos, pode-se observar os dados referentes ao indicador D, índice de adequação idade/ anos de escolaridade, da população de 9 a 16 anos - Brasil e grandes regiões.

\section{Índice de Adequação Idade-Anos de Escolaridade por idade Brasil, 2008}

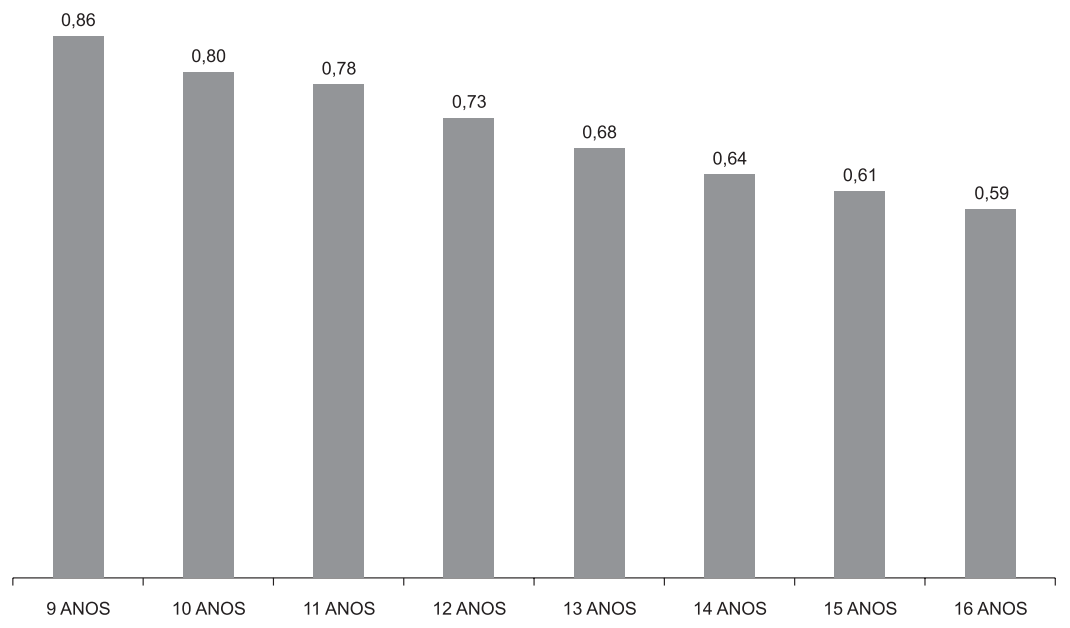

Fontes: IBGE, Pesquisa Nacional por Amostra de Domicilios, PNAD; elaborado por Inep/DTDIE.

${ }^{83}$ INSTITUTO DE PESQUISA ECONÔMICA APLICADA. Objetivos de desenvolvimento do milênio. Relatório Nacional de acompanhamento. IPEA: Brasília, 2010. Disponível em: $<$ http://www.ipea. gov.br>. Acesso em: 11 maio 2010. p. 46.

${ }^{84}$ INSTITUTO DE PESQUISA ECONÔMICA APLICADA. Objetivos de desenvolvimento do milênio. Relatório Nacional de acompanhamento. IPEA: Brasília, 2010. Disponível em: <http://www.ipea. gov.br>. Acesso em: 11 maio 2010. p. 47. 
A distorção indicada cresce ao longo do processo de escolarização, visto que 41\% dos jovens de 16 anos em 2008 encontravam-se em situação de atraso escolar. Assim, o atraso que aos 9 anos é de 14\%, cresce em média 3,85\% a.a. de idade escolar, sendo mais acentuado na passagem dos 9 para os 10 anos, 0,6 p.p.

\section{Índice de Adequação Idade-Anos de Escolaridade da população de 9 a 16 anos de idade - Brasil e regiões, 200}

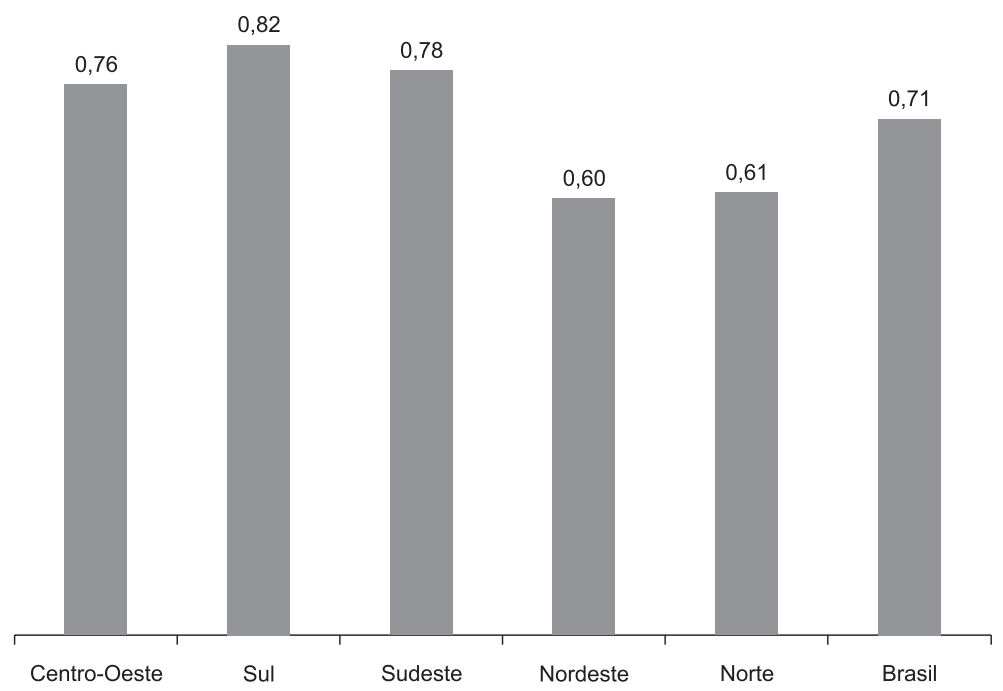

Fontes: IBGE, Pesquisa Nacional por Amostra de Domicílios, PNAD; elaborado por Inep/DTDIE.

Se tomarmos por base a média nacional, é possível verificar que $71 \%$ dos brasileiros na faixa de população de 9 a 16 anos encontram-se em situação adequada. "Em grande medida, esse alto índice de distorção idade/série é devido às desigualdades regionais, que, por sua vez, estão diretamente relacionadas às desigualdades de renda". ${ }^{85}$ Observe-se que abaixo da média nacional situam-se a Região Norte e Nordeste, estando ambas a mais de 20 p. p. abaixo da Região Sul.

${ }^{85}$ INSTITUTO DE PESQUISA ECONÔMICA APLICADA. Objetivos de desenvolvimento do milênio. Relatório Nacional de acompanhamento. IPEA: Brasília, 2010. Disponível em: <http://www.ipea. gov.br>. Acesso em: 11 maio 2010. p. 47. 
Não obstante tais desigualdades, houve um grande aumento da taxa de conclusão de ensino médio, é o que demonstram os dados vinculados ao indicador C, que registra a proporção de pessoas de 11 e 12 anos que tenham concluído a $4^{\mathrm{a}}$ série do EF e pessoas de 18 anos concluíram esse nível de ensino:

Proporções de pessoas de 11 e 12 anos que tenham concluído a $4^{\text {a }}$ série do ensino fundamental, e de 18 anos que tenham concluído a $8^{a}$ série do ensino fundamental - Brasil, 1992*, 2005 e 2008

\begin{tabular}{|l|c|c|c|}
\hline & $\mathbf{1 9 9 2}$ & $\mathbf{2 0 0 5}$ & $\mathbf{2 0 0 8}$ \\
\hline 11 anos & 29,0 & 56,7 & 50,9 \\
\hline 12 anos & 42,2 & 75,2 & 72,3 \\
\hline 18 anos & 34,0 & 68,4 & 75,2 \\
\hline
\end{tabular}

Exclusive a população rural dos estados de RO, AC, AM, RR, PA e AP.

Fonte: IBGE. Pesquisa Nacional por amostra de Domicílios, PNDA; elaborado por Inep/ DTDIE.

Percebe-se certo recuo na conclusão do EF e redução da diferença entre a conclusão do EF aos 12 e EM aos 18 anos de idade, que em 1992 era de 8,2 p.p. em favor do EF passou a ser 2,9 p.p. em favor do EM. Isso ocorreu dado o decréscimo no primeiro de 2,9 p.p. e o crescimento de 6,8 p.p. no segundo, EM.

Por fim, o indicador E refere-se à taxa de alfabetização das pessoas de $15 \mathrm{a}$ 24 anos de idade, segundo sexo, cor/raça e situação do domicílio - Brasil e grandes regiões, e os dados correspondentes são apresentados na tabela abaixo: 
Taxa de alfabetização das pessoas de 15 a 24 anos de idade, segundo sexo, cor/raça e localização Brasil e regiões, 1992*, 2005 e 2008

\begin{tabular}{|l|c|c|c|}
\hline \multirow{2}{*}{ Características Selecionadas } & \multicolumn{3}{|c|}{ Fundamental 7 a 14 anos } \\
\cline { 2 - 4 } & $\mathbf{1 9 9 2}$ & $\mathbf{2 0 0 5}$ & $\mathbf{2 0 0 8}$ \\
\hline Total & 91,3 & 97,2 & 97,8 \\
\hline Norte & 94,0 & 96,8 & 97,5 \\
\hline Nordeste & 80,0 & 93,7 & 95,7 \\
\hline Sudeste & 96,5 & 98,9 & 99,0 \\
\hline Sul & 96,8 & 98,8 & 99,0 \\
\hline Centro-Oeste & 95,4 & 98,7 & 98,8 \\
\hline Sexo & \multicolumn{5}{|c|}{} \\
\hline Masculino & 89,2 & 96,2 & 97,2 \\
\hline Feminino & 93,5 & 98,1 & 98,5 \\
\hline Cor/Raça & 95,6 & 98,4 & 98,7 \\
\hline Branca & 86,8 & 96,0 & 97,3 \\
\hline Preta e Parda & 94,8 & 92,6 & 94,6 \\
\hline Localização & 78,9 & 98,1 & 98,5 \\
\hline Rural & \multicolumn{5}{|l}{} \\
\hline Urbana & \multicolumn{5}{|c|}{} \\
\hline Exclusive popuçã & & \\
\hline
\end{tabular}

Exclusive a população rural dos estados de RO, AC, AM, RR, PA e AP.

Fonte: IBGE. Pesquisa Nacional por amostra de Domicílios, PNDA; elaborado por Inep/ DTDIE.

Percebe-se que o analfabetismo entre a população de 15 a 24 anos de idade sofreu a maior redução na Região Nordeste, de 15,7 p.p, entretanto ainda está 2,1 p. p. abaixo da média nacional em 2008, que é de 97,8\%. As desigualdades entre as regiões também sofreram decréscimo, na medida em que a desigualdade entre o Nordeste e o Sul que em 1992 correspondia a 16,8 p.p. passou a ser de 3,3 p.p, ou seja, redução de 13,5 p. p. A desigualdade entre o sexo feminino e masculino reduziu 1,3 p.p. de 1992 a 2008, enquanto ambos os índices de alfabetização cresceram na ordem de 5 e 8 p.p. respectivamente; entre cor/raça a desigualdade foi reduzida em mais da metade, passando de 8,8 para 4 p.p. após o crescimento na taxa de alfabetização da população branca em 3,1 p. p. e preta/parda em 11,5 p.p.

Já em relação à localização, percebe-se que houve um decréscimo da alfabetização da área rural se comparados os anos de 1992 e 2008, entretanto, por o ano 
de 2005 demonstrar uma queda em relação a 1992, percebe-se o crescimento de 4 p.p. de 2008 em relação a 2005. O maior crescimento da taxa de alfabetização nessa faixa populacional foi na área urbana, na ordem de 19,7 p.p. de forma a ultrapassar a da área rural.

Dessa forma, é possível constatar que existe uma tendência de equiparação da escolarização líquida entre os quintos de renda, não obstante, no Ensino Médio, ser perceptível a relação entre a distorção idade-série e a baixa renda., também existe uma crescente distorção idade-série, em média de 3,85\%, conforme os dados de 2008. Outro fator que contribui para tal distorção é a região, que, por sua vez, relaciona-se às desigualdades de renda. Nesse sentido, é possível verificar a proposição de Amartya Sen quanto à relação entre pobreza de rendas e de capacidades; assim, tendo em vista que existe uma reciprocidade entre ambas as pobrezas, pode-se perceber a formação de um círculo vicioso nas regiões Norte e Nordeste.

\subsection{Analfabetismo entre jovens e adultos}

$\mathrm{O}$ analfabetismo relaciona-se tanto às insuficientes $\mathrm{e}$ desiguais oportunidades de acesso e permanência na escola na idade adequada, quanto ao fracasso dos sistemas públicos de ensino que geram jovens analfabetos de forma a alimentar um círculo vicioso de má qualidade de ensino, pois geram professores despreparados. ${ }^{86}$ Além destes, pode-se observar a presença de outros dois fatores, o primeiro relacionado à desmotivação de permanência no ensino tendo em vista o baixo retorno à educação ${ }^{87}$, e o segundo, à falha na estruturação do ensino a fim de adequar-se às camadas mais pobres da população. ${ }^{88}$

\footnotetext{
${ }^{86}$ INSTITUTO DE PESQUISA ECONÔMICA APLICADA. Brasil em desenvolvimento: estado, planejamento e políticas públicas. Brasília: IPEA, 2009. Disponível em: <http://www. ipea.gov.br/portal/ index.php?option=com_content \& view=article\&id=239\&Itemid=6 $>$. Acesso em: 11 maio 2010. p. 619.

${ }^{87}$ Para observar a relação entre educação e a perspectiva microeconômica ver IOSCHPE, Gustavo. A ignorância custa um mundo: o valor da educação no desenvolvimento do Brasil. São Paulo: Francis, 2004. p. 152.

${ }^{88}$ CASTRO, Cláudio de Moura. Educação brasileira: consertos e remendos. Rio de Janeiro: Rocco, 2007. p. 65.
} 
A análise do analfabetismo foi estruturada, levando em consideração sua alta incidência entre adultos e, principalmente, entre idosos, a partir da evolução do analfabetismo, seguindo a linha de recortes clássicos. ${ }^{89} \mathrm{O}$ período a ser analisado é o de $1988-2007^{90}$ com destaque ao quadriênio 2004-2007 tendo em vista que a área rural da Região Norte passou a ser abrangida pela Pesquisa Nacional por Amostra de Domicílios - PNAD - a partir de 2004. ${ }^{91}$ A seguir, será abordada a evolução do analfabetismo em ambos os períodos, para posteriormente adentrar na questão da frequência de adultos e idosos à escola..$^{92}$

Vale destacar uma crítica feita sobre a atuação governamental voltada para a erradicação do analfabetismo entre adultos, tendo em vista a atual composição da estrutura:

Escolher como alvo os que não estão mais na escola é escolher uma população que decidiu abandoná-la por conta de reprovações sucessivas e um crescente sentimento de frustração [...]. O Brasil tem que ter hoje a coragem de optar pelo mais urgente e mais fácil. Urge melhorar a escola regular para que os seus alunos nem a abandonem prematuramente nem se formem sabendo um pouco mais do que assinar o nome. ${ }^{93}$

Apesar de se tratar de uma crítica com o fito construtivo à estrutura educacional, entende-se que a retirada de políticas voltadas para a redução de analfabetismo entre adultos seria estagnar a situação de uma parcela da população que já foi excluída do sistema, ou por falhas deste ou por motivos distintos, em uma condição que não era para existir.

\footnotetext{
${ }^{89}$ Faixa etária, renda, cor/raça, situação do domicílio etc.

${ }^{90} \mathrm{O}$ que trará informações complementares às do Relatório Nacional de Acompanhamento dos ODM feito pelo IPEA.

${ }^{91}$ INSTITUTO DE PESQUISA ECONÔMICA APLICADA. Brasil em desenvolvimento: estado, planejamento e políticas públicas. Brasília: IPEA, 2009. Disponível em: <http:// www.ipea.gov.br/portal/index.php?option=com_content\&view=article\&id=239\&Item $\mathrm{id}=6>$. Acesso em: 11 maio 2010. p. 619.

${ }_{92}$ Restrito ao período de 2004-2007.

${ }^{93}$ CASTRO, Cláudio de Moura. Educação brasileira: consertos e remendos. Rio de Janeiro: Rocco, 2007. p. 50.
} 
Concordar na manutenção de pobreza de capacidades da parcela adulta não parece estar de acordo com o princípio da educação como direito de todos. Ademais, nada indica que o direcionamento de um programa para erradicação do analfabetismo entre adultos impeça a readequação da estrutura de ensino de forma a romper com o ciclo de formação de adultos analfabetos, na parte em que lhe cabe.

\subsubsection{Trajetória do analfabetismo}

A faixa da população analisada é de 15 anos ou mais. No período de 19882007 a redução foi de 47\%. Enquanto a redução entre jovens de 15 a 24 anos foi de $78 \%$, entre a população de 40 anos ou mais foi de $45,7 \%$, não foi maior, pois a população de 40 anos ou mais não beneficiada de forma suficiente pelos programas de alfabetização de adultos. ${ }^{94}$

O período de 2004 a 2007 demonstrou uma queda de 1,4\%, vindo, em 2007, o índice médio nacional a situar-se em 10\%. Analisando por regiões, houve a ampliação das desigualdades, uma vez que a Região Nordeste teve o menor decrescimento do analfabetismo. O mesmo ocorreu em relação à área rural e urbana, mantendo a concentração de analfabetismo na primeira. Em relação à divisão de faixa etária em razão da área, houve o decrescimento de analfabetos entre jovens da área rural, que "está relacionada à migração para as cidades de parte deste estrato

${ }^{94}$ Conforme apontado: "Apesar de esta maior redução entre os jovens ser compreensível e até desejada, à medida que se amplia o acesso à escola e às gerações mais novas, deve-ser reconhecer que entre os adultos e, sobretudo idosos, a erradicação do analfabetismo está longe de concretizar-se. Desse modo, a taxa de analfabetismo da população de 15 anos ou mais em 2007 era igual à dos jovens de 15 a 24 anos, duas décadas antes." INSTITUTO DE PESQUISA ECONÔMICA APLICADA. Políticas sociais: acompanhamento e análise: 20 anos da Constituição Federal. 17. ed. Brasília: IPEA, 2009. v. 2. p. 50.

${ }^{94}$ Entre 2004 e 2007, a população de 15 a 29 anos residente em áreas urbanas cresceu 1,8\%, enquanto no meio rural esse estrato populacional decresceu $1,9 \%$. No mesmo período, houve redução de cerca de 240 mil analfabetos nessa faixa etária entre os residentes nas cidades, ao passo que na zona rural a diminuição foi de quase 269 mil.” INSTITUTO DE PESQUISA ECONÔMICA APLICADA. Brasil em desenvolvimento: estado, planejamento e políticas públicas. Brasília: IPEA, 2009. Disponível em: <http://www.ipea.gov.br/portal/ index.php?option $=$ com_content $\&$ view $=$ article $\& i d=239 \&$ Itemid $=6>$. Acesso em: 12 maio 2010. p. 620. 
populacional". ${ }^{95} 96$ Enquanto dentre os idosos, "devido ao aumento do número de idosos analfabetos na área rural e à pequena redução ocorrida entre os residentes nas áreas urbanas", 97 a representação destes em relação ao todo passou por um crescimento de 3\% em relação a 2004, chegando a 40 \% em 2007.

No período de 2004-2007, o aumento do contingente de idosos analfabetos na área rural foi de 132 mil analfabetos, "esse aumento se deve aos adultos que tinham pelo menos 57 anos, em 2004, e que não foram alfabetizados".98 Assim, a não alfabetização em idade adequada dessa faixa populacional não pode ser compensada em outro período, o que levou à sua manutenção durante toda a vida. Outro aspecto a ser considerado é o aumento de adultos analfabetos de 40 anos ou mais, que com o acréscimo de $4 \%$, chegou a representar quase $77 \%$ do todo, "com isso, a incidência do analfabetismo entre idosos passou a ser quase dez vezes maior que na faixa etária de 15 a 29 anos".99 Destaca-se que a redução da taxa de analfabetismo deve ser olhada com cautela, pois a redução de $1 \%$ na faixa de 15 a 29 anos corresponde a 19,5 mil jovens aproximadamente, e 1\% na faixa de 60 anos ou mais corresponde 3,5 mil idosos aproximadamente. ${ }^{100}$

${ }^{95}$ INSTITUTO DE PESQUISA ECONÔMICA APLICADA. Brasil em desenvolvimento: estado, planejamento e políticas públicas. Brasília: IPEA, 2009. Disponível em: <http:// www.ipea.gov.br/portal/index.php?option $=$ com_content $\& v i e w=$ article\&id $=239 \&$ Item $\mathrm{id}=6>$. Acesso em: 12 maio 2010. p. 620.

${ }^{97}$ INSTITUTO DE PESQUISA ECONÔMICA APLICADA. Brasil em desenvolvimento: estado, planejamento e políticas públicas. Brasília: IPEA, 2009. Disponível em: <http:// www.ipea.gov.br/portal/index.php?option=com_content\&view=article\&id=239\&Item $\mathrm{id}=6>$. Acesso em: 12 maio 2010. p. 620.

${ }^{98}$ INSTITUTO DE PESQUISA ECONÔMICA APLICADA. Brasil em desenvolvimento: estado, planejamento e políticas públicas. Brasília: IPEA, 2009. Disponível em: <http:// www.ipea.gov.br/portal/index.php?option=com_content\&view=article\&id=239\&Item $\mathrm{id}=6>$. Acesso em: 12 maio 2010. p. 620.

99 INSTITUTO DE PESQUISA ECONÔMICA APLICADA. Brasil em desenvolvimento: estado, planejamento e políticas públicas. Brasília: IPEA, 2009. Disponível em: <http:// www.ipea.gov.br/portal/index.php?option=com_content\&view=article\&id=239\&Item $\mathrm{id}=6>$. Acesso em: 12 maio 2010. p. 621.

${ }^{100}$ Por exemplo, na faixa de 15 a 29 anos, a queda de $26 \%$ na taxa de analfabetismo foi acompanhada de redução de 509 mil jovens analfabetos. No entanto, a queda de apenas $11 \%$ na taxa de analfabetismo na faixa de 60 anos ou mais gerou aumento líquido da ordem de 39 mil analfabetos". INSTITUTO DE PESQUISA ECONÔMICA APLICADA. Brasil em desenvolvimento: estado, planejamento e políticas públicas. Brasília: IPEA, 2009. Disponível em: <http://www.ipea.gov.br/portal/index.php?option=com_content\&view=article\&id= 239\&Itemid=6>. Acesso em: 12 maio 2010. p. 621. 
O cálculo de analfabetismo entre os idosos é resultado de analfabetos provenientes da faixa etária imediatamente anterior, de analfabetos que faleceram no período e de pessoas alfabetizadas no período de análise, de forma que o aumento ocorreu devido ao maior ingresso de analfabetos que a redução proporcionada pelos dois outros fatores.

Dessa forma, percebe-se que há um nó crítico na alfabetização de jovens e adultos, o que revela a insuficiência de promover a erradicação ou a diminuição do analfabetismo dessa faixa etária. ${ }^{101}$

Quanto às variáveis i) raça/cor e ii) renda são postas sob análise. Houve o crescimento de $2 \%$ de negros analfabetos, o que se deve ao "crescimento desproporcional da população negra nos últimos anos.” ${ }^{102}{ }^{103}$ No período 1988-2007, "houve redução de 50\% no índice de analfabetismo entre mulheres de 15 anos ou mais, enquanto a queda entre os homens foi de 44\%", passando a liderança a ser exercida pelos homens. ${ }^{104}$

${ }^{101}$ INSTITUTO DE PESQUISA ECONÔMICA APLICADA. Brasil em desenvolvimento: estado, planejamentoepolíticaspúblicas. Brasília:IPEA,2009.Disponívelem: $<$ http://www. ipea.gov.br/portal/index.php?option=com_content\& view=article\&id=239\&Itemid=6>. Acesso em: 12 maio 2010. p. 621.

102 Entre 2004 e 2007, a população branca de 15 anos ou mais teria crescido aproximadamente $2,4 \%$, enquanto o aumento da população negra teria sido de $10,9 \%$. [..] este aumento desproporcional da população negra estaria relacionado ao fato de que maior número de pessoas passou a se reconhecer como tal. Em razão disso, pode se inferir que entre estas haveria proporção significativa de analfabetos". INSTITUTO DE PESQUISA ECONÔMICA APLICADA. Brasil em desenvolvimento: estado, planejamento e políticas públicas. Brasília: IPEA, 2009. Disponível em: <http://www.ipea.gov.br/portal/index. php? option=com_content $\&$ view=article\&id=239\&Itemid=6>. Acesso em: 12 maio 2010. p. 621.

103 INSTITUTO DE PESQUISA ECONÔMICA APLICADA. Brasil em desenvolvimento: estado, planejamentoepolíticaspúblicas. Brasília:IPEA,2009.Disponívelem: $<$ http://www. ipea.gov.br/portal/index.php?option=com_content\& view=article\&id=239\&Itemid=6 $>$. Acesso em: 12 maio 2010. p. 621.

${ }^{104}$ Especificamente no ano de 2001. INSTITUTO DE PESQUISA ECONÔMICA APLICADA. Políticas sociais: acompanhamento e análise: 20 anos da Constituição Federal. 17. ed. Brasília: IPEA, 2009. v. 2. p. 50. 
Quanto à renda, o analfabetismo diminuiu na faixa populacional que recebe até um salário mínimo - SM e aumentou na que recebe de um a dois. ${ }^{105}$ Ademais, diante dos dados apresentados, percebeu-se que os reais analfabetos não estavam sendo alcançados pelo Brasil Alfabetizado, o que ensejou a alteração da lógica de execução do programa. ${ }^{106}$

Dessa forma, percebe-se a lenta redução do analfabetismo no Brasil. Esta se vincula estreitamente à "ampliação de desigualdades que, historicamente, foram sempre elevadas”. Os grupos que tiveram pequenos avanços “- população da Região Nordeste, residentes de áreas rurais, e idosos, correspondem significativa parcela da população brasileira". ${ }^{107}$ Quanto ao perfil do analfabetismo ${ }^{108}$, as seguintes características são reveladas:

i) é bem mais acentuado na população negra; ii) as regiões menos desenvolvidas, os municípios de pequeno porte e as zonas rurais apresentam os piores índices; iii) está fortemente concentrado nos segmentos de baixa renda; e iv) o percentual e a quantidade de analfabetos se ampliam nos estratos de idade mais avançada. Além disso, constatou-se que a taxa de

${ }^{105}$ É possível que essa mobilidade entre a primeira e a segunda faixa de renda tenha sido favorecida pelas políticas sociais implementadas e/ou intensificadas a partir de 2003: Programa Bolsa Família (PBF), Benefício de Prestação Continuada (BPC), Renda Mensal Vitalícia (RMV), Aposentadoria Rural etc." INSTITUTO DE PESQUISA ECONÔMICA APLICADA. Brasilem desenvolvimento: estado, planejamento e políticas públicas. Brasília: IPEA, 2009. Disponível em: <http://www.ipea.gov.br/portal/index.php?option=com_ content\&view=article\&id $=239 \&$ Itemid=6>. Acesso em: 12 maio 2010. p. 622 .

106 [...] passa a priorizar recursos para os municípios com taxa de analfabetismo acima de $35 \%$ e faixa etária de 15 a 29 anos. Além disso, os municípios terão papel preponderante na implementação do programa, pois caberão a eles a maior parte dos recursos previstos e a responsabilidade pelo recrutamento e pela capacitação de professores das redes públicas de ensino. Por fim, a concessão de bolsa pecuniária aos professores alfabetizadores, sobretudo aos dos municípios mais pobres, poderá contribuir para a melhoria de seu desempenho. INSTITUTO DE PESQUISA ECONÔMICA APLICADA. Brasil em desenvolvimento: estado, planejamento e políticas públicas. Brasília: IPEA, 2009. Disponível em: <http://www.ipea.gov.br/portal/index.php?option=com_content\& view=article\&id=239\&Itemid=6>. Acesso em: 12 maio 2010. p. 622 .

107 INSTITUTO DE PESQUISA ECONÔMICA APLICADA. Brasil em desenvolvimento: estado, planejamento epolíticaspúblicas. Brasília:IPEA, 2009.Disponívelem: $<$ http://www. ipea.gov.br/portal/ index.php?option=com_content $\&$ view=article\&id=239\&Itemid $=6>$. Acesso em: 12 maio 2010. p. 622.

${ }^{108}$ Dados de 2007. 
analfabetismo dentro de uma mesma geração é pouco sensível a mudanças com o passar dos anos. Seu declínio está ocorrendo pela escolarização da população mais nova e pela própria dinâmica populacional, com a morte dos idosos analfabetos. ${ }^{109}$

Percebe-se que a conjugação dos fatores de exclusão forma um cinturão de isolamento, que o torna impenetrável pelo sistema educacional, conforme as características visualizadas. Também é perceptível a relação entre pobreza de rendas e pobreza de capacidades, tendo em vista a forte concentração nos segmentos de baixa renda.

\subsubsection{A frequência de adultos e idosos à escola}

A questão do analfabetismo entre adultos e idosos persiste, além dos fatores apontados, devido à "baixa inserção destes segmentos populacionais em programas de alfabetização e educação entre jovens e adultos". ${ }^{110} \mathrm{Ou}$ seja, a baixa inserção é reflexo da falta de permeabilidade da faixa de população que se encontra no quadro de exclusão social. Ademais, houve uma significativa redução da frequência à escola entre adultos na faixa etária de 40 anos ou mais, o que pode ter ocorrido devido à reformulação do Programa Brasil Alfabetizado no ano de 2007.111 112

109 CASTRO, Jorge Abrahão de; DUARTE, Bruno de Carvalho. Descentralização da educação pública no Brasil: trajetória dos gastos e das matrículas. Brasília: IPEA, 2008. (Texto para Discussão, n. 1352). p. 58.

${ }^{110}$ INSTITUTO DE PESQUISA ECONÔMICA APLICADA. Brasil em desenvolvimento: estado, planejamentoepolíticaspúblicas. Brasília:IPEA,2009.Disponívelem: $<$ http://www. ipea.gov.br/portal/index.php?option=com_content \&view=article\&id=239\&Itemid=6>. Acesso em: 12 maio 2010. p. 622.

111 Por exemplo, em 2005, havia mais de 2 milhões de alfabetizandos cadastrados, mas a redução do número de analfabetos de 15 anos ou mais, entre 2005 e 2006, foi de apenas 600 mil. No biênio seguinte, ampliou-se ainda mais a diferença entre o número de beneficiários do programa e o total de pessoas que deixaram a condição de analfabetas". INSTITUTO DE PESQUISA ECONÔMICA APLICADA. Brasil em desenvolvimento: estado, planejamento e políticas públicas. Brasília: IPEA, 2009. Disponível em: <http:// www.ipea.gov.br/portal/index.php?option=com_content\&view=article\&id=239\&Item $\mathrm{id}=6>$. Acesso em: 12 maio 2010. p. 624 .

112 INSTITUTO DE PESQUISA ECONÔMICA APLICADA. Brasil em desenvolvimento: estado, planejamentoepolíticas públicas. Brasília:IPEA, 2009.Disponívelem: $<$ http://www. ipea.gov.br/portal/ index.php?option=com_content \&view=article\&id=239\&Itemid=6>. Acesso em: 12 maio 2010. p. 622-623. 
As conclusões que podem ser auferidas dos dados apontados não diferem de forma vertiginosa em relação às conclusões do Relatório dos ODM no que toca às características da população não incluída no sistema de ensino. Existe uma intensificação nos investimentos para impedir o aparecimento do analfabetismo nas primeiras faixas etárias, entretanto, dadas as condições de desigualdade social, ocorre a distorção idade/série e consequente saída da pessoa da estrutura de ensino, acrescida da baixa possibilidade de re-inserção.

\subsection{Evolução do desempenho em educação básica}

A qualidade da educação é uma das questões mais preocupantes, pois além de contribuir para a não formação de gerações de analfabetos, como visto anteriormente, é uma necessidade do país, tanto em termos de desenvolvimento quanto pela racionalidade de aplicação dos recursos públicos, que, de certa maneira, acaba por corroborar com a primeira colocação, pois se trata do retorno a um investimento. Teóricos apontam que "o grande problema do Brasil não é gastar pouco, mas gastar mal."113

Antes de adentrarmos no período de 2004 a 2007, vale trazer dados que revelam a situação educacional dos alunos no Brasil por meio do Sistema Nacional de Avaliação da Educação Básica - $\mathrm{SAEB}^{114} \mathrm{O}$ nível esperado de desempenho no SAEB, por série, pode ser visto na tabela abaixo.

113 CASTRO, Cláudio de Moura. Educação brasileira: consertos e remendos. Rio de Janeiro: Rocco, 2007. p. 33. Em mesmo sentido se posiciona IOSCHPE, Gustavo. A ignorância custa um mundo: o valor da educação no desenvolvimento do Brasil. São Paulo: Francis, 2004. p. 143.

${ }^{114} \mathrm{O}$ teste é aplicado a cada dois anos e mede as competências dos alunos de $4^{\mathrm{a}}$ a $8^{\mathrm{a}}$ séries do Ensino Fundamental e $3^{\text {a }}$ série do Ensino Médio em Português, Matemática e outras disciplinas. Suas dimensões são gigantescas: a edição de 2001, por exemplo, avaliou 287 mil alunos de quase 7 mil escolas de todo o país, das redes municipal, estadual e privada. O teste é considerado de excelente qualidade por especialistas em avaliação educacional e seus resultados têm impacto significativo na maneira como as secretarias de Educação pensam seus cursos. Para mais informações sobre a metodologia utilizada BRASIL. Ministério da Educação. Primeiros resultados: médias de desempenho do SAEB/2005 em perspectiva comparada. Brasília: INEP, 2007. Disponível em: <http://www.inep.gov.br/ download/saeb/2005/SAEB1995_2005.pdf>. Acesso em: 13 mar. 2010. 


\begin{tabular}{|c|c|}
\hline Pontuação & Série \\
\hline De 0 a 100 & Insignificante \\
\hline $101-175$ & Fim da $2^{\text {a }}$ série Fundamental \\
\hline $176-200$ & Fim da $4^{\text {a }}$ série Fundamental \\
\hline $201-325$ & Fim da $8^{\text {a }}$ série Fundamental \\
\hline $326-400$ & Fim da $3^{\text {a }}$ série do Ensino Médio \\
\hline
\end{tabular}

O desempenho real foge das expectativas, veja-se ${ }^{115}$

\begin{tabular}{|c|c|c|c|c|c|c|c|}
\hline Série & \multicolumn{7}{|c|}{ Matemática } \\
\hline & 95 & 97 & 99 & 01 & 03 & 05 & 07 \\
\hline $4^{\text {a }} \mathrm{EF}$ & 191 & 191 & 181 & 176 & 177 & 182 & 190 \\
\hline $8^{\text {a }} \mathrm{EF}$ & 253 & 250 & 246 & 243 & 245 & 239 & 250 \\
\hline $3^{\circ} \mathrm{EM}$ & 282 & 289 & 280 & 277 & 279 & 271 & 288 \\
\hline
\end{tabular}

\begin{tabular}{|c|c|c|c|c|c|c|c|}
\hline Série & \multicolumn{8}{|c|}{ Português } \\
\hline & 95 & 97 & 99 & 01 & 03 & 05 & 07 \\
\hline $4^{\text {a }} \mathrm{EF}$ & 188 & 186 & 171 & 165 & 169 & 172 & 186 \\
\hline $8^{\text {a }} \mathrm{EF}$ & 256 & 250 & 233 & 235 & 232 & 231 & 250 \\
\hline $3^{\circ} \mathrm{EM}$ & 290 & 284 & 267 & 262 & 267 & 257 & 283 \\
\hline
\end{tabular}

Quanto aos alunos da $4^{\text {a }}$ série, eles têm o desempenho esperado em Matemática correspondente à sua série, entretanto, numa tendência instável, chegando em 2003, perto do nível esperado para alunos da 2a série. Depois desse registro, não obtiveram ainda, em 2007, a pontuação registrada em 95. Dentro da faixa 176200, o máximo foi de 191. Em Português, chegaram a ter o desempenho adequado à série em 1995 e 1997, caindo bruscamente nos anos seguintes, atingindo o desempenho esperado para a 2a série do EF, nos anos de 1999 a 2005. A pontuação adequada voltou a ser alcançada em 2007. Ademais, constata-se que dentro da faixa 176-200, o máximo foi de 186 , ou seja, $44 \%$ da faixa.

\footnotetext{
${ }^{115}$ Dados disponíveis em: < http://www.inep.gov.br/download/saeb/2005/ SAEB1995_2005. pdf e http://www.inep.gov.br/download/Ideb/Nota_Tecnica_n1_ concepcao IDEB.pdf> Acesso em: 18 jan. 2010.
} 
Os alunos da $8^{\mathrm{a}}$ série têm o desempenho tanto em Português como em Matemática compatível com o nível de ensino enquadrados, entretanto, dentro da faixa 201-325 pontos, pontuação máxima atingida em Português foi de 253 em 1995, e a pontuação obtida em 2007 equivale a de 1997, sendo que a pior foi obtida em 2005, com 239 pontos. Em Matemática, a situação não se distingue muito; a pontuação em 2007, 250, não equivale à obtida em 1995, que foi de 256.

Os alunos da $3^{\text {a }}$ série do Ensino Médio não conseguiram atingir, em nenhum dos anos analisados, a pontuação referente à sua série. Uma catástrofe atenuada pelo resultado de 2007, que rompeu com a tendência decrescente de pontuação no SAEB, sem alcançar, no entanto, a pontuação máxima do período. Tendo em vista o quadro da qualidade da educação no Brasil, vejamos algumas medidas que foram adotadas. Tal movimento pode ser explicado pelo aumento da estrutura educacional, e consequente aumento de matrículas, sem ser acompanhado pelas condições suficientes à manutenção e superação da qualidade de ensino.

Conforme PDE, “a principal meta estabelecida é atingir o índice de 6 pontos, em 2021, o qual correspondia ao desempenho escolar médio dos países da Organização para Cooperação e Desenvolvimento Econômico (OCDE), à época da concepção do plano". ${ }^{116}$ Para tanto, foi feito o uso do IDEB ${ }^{117}$ "principal

${ }^{116}$ INSTITUTO DE PESQUISA ECONÔMICA APLICADA. Brasil em desenvolvimento: estado, planejamento e políticas públicas. Brasília: IPEA, 2009. Disponível em: <http:// www.ipea.gov.br/portal/index.php?option=com_content\&view=article\&id=239\&Item $\mathrm{id}=6>$. Acesso em: 12 maio 2010. p. 618 .

117 Trata-se de indicador que expressa, por meio de escala numérica, a evolução do desempenho do sistema educacional, a partir das seguintes variáveis: i) proficiência em exames nacionais; e ii) taxa de aprovação. Ou seja, O Ideb é um indicador de qualidade educacional que combina informações de desempenho em exames padronizados (Prova Brasil ou Saeb) - obtido pelos estudantes ao final das etapas de ensino ( $4^{\mathrm{a}}$ e $8^{\mathrm{a}}$ séries do Ensino Fundamental e $3^{\text {a }}$ série do Ensino Médio) - com informações sobre rendimento escolar (aprovação). Para mais informações sobre o IDEB: http://www.inep.gov.br/ download/Ideb/Nota_Tecnica_n1_concepcaoIDEB.pdf 
indicador de monitoramento da evolução de desempenho do sistema educacional brasileiro". ${ }^{118} \mathrm{O}$ primeiro ano de aplicação do IDEB $^{119}$ foi o de $2005 .{ }^{120}$

Nas escolas de $1^{\text {a }}$ a $4^{\text {a }}$ série, considerando o desempenho insuficiente abaixo de 50\% da meta estabelecida para 2021, houve redução entre as escolas municipais e estaduais nas quais a proporção baixou de $10 \%$, chegando a $12 \%$ e $13 \%$ respectivamente. As escolas municipais e estaduais de $5^{\mathrm{a}}$ a $8^{\mathrm{a}}$ obtiveram $18 \%$ e $17 \%$, respectivamente.

Destaca-se que houve ampliação de desigualdade do IDEB entre as regiões Norte/Nordeste e Sul/Sudeste/Centro-Oeste

[...] as regiões Norte e Nordeste, que apresentavam os piores resultados em 2005, foram as que menos evoluíram em relação a tal indicador. Se, nas regiões Sul, Sudeste e CentroOeste, a proporção de escolas com baixo desempenho foi reduzida entre $31 \%$ e $57 \%$, naquelas duas regiões a redução oscilou entre 13\% e 17\%. Portanto, ampliou-se a

${ }_{118}$ A Prova Brasil e o Saeb são instrumentos de avaliação do sistema educacional brasileiro criados para auxiliar no desenvolvimento e implementação de políticas públicas educacionais. Avaliam o que os alunos sabem em termos de habilidades e competências, e não simplesmente de conteúdo. Ambas são aplicadas a cada dois anos a alunos de séries finais de ciclos da Educação Básica: $4^{\mathrm{a}}$ e $8^{\mathrm{a}}$ série do Ensino Fundamental (caso da Prova Brasil) e também $3^{\circ}$ ano do Ensino Médio (no caso do Saeb).

[...] A participação é voluntária, entretanto, é importante às escolas, municípios e unidades da Federação participarem das avaliações para terem seu Índice de Desenvolvimento da Educação Básica (Ideb) calculado, e, conseqüentemente, participar dos programas baseados nas metas previstas pelo Compromisso Todos pela Educação do MEC.

As médias de desempenho na Prova Brasil e no Saeb subsidiam o cálculo do Ideb e, a partir dele e das demais informações apuradas nas provas, o MEC e as secretarias de Educação definem ações voltadas para a correção de distorções e direcionam seus recursos técnicos e financeiros para as áreas prioritárias, visando ao desenvolvimento do sistema educacional brasileiro e à redução das desigualdades existentes nele. Disponível em: http://provabrasil.inep.gov.br/index.php?option=com_content\&task=view\&id=33\& Itemid $=60$ Acesso realizado em: 18 jan. 2010.

119 O cálculo do IDEB é realizado segundo diversos recortes ou categorias: i) por nível de ensino - anos iniciais do Ensino Fundamental; anos finais do Ensino Fundamental; Ensino Médio; e ii) por dependência administrativa da escola - pública: federal, estadual e municipal; e privada.

${ }^{120}$ Dessa forma, apesar de pequeno o período analisado, é importante a análise de tais dados que revelam uma nova metodologia utilizada pela MEC. 
desigualdade, no período 2005-2007, entre as regiões com melhor e pior desempenho em termos de IDEB. ${ }^{121}$

Especificamente quanto ao SAEB, percebe-se que a educação básica em termos de qualidade de ensino, configura-se em forma de pirâmide, uma vez que quanto maior a série menor o desempenho dos alunos em relação ao desejável, de forma que a pontuação obtida pelos anos da $3^{\text {a }}$ série do EM não ultrapassa o esperado para os alunos da $8^{\text {a }}$ série do EF. Ademais, a pontuação não progrediu com o passar dos anos, entretanto, no ano de 2007 houve uma recuperação em relação aos anos anteriores que estavam sob uma tendência decrescente de resultado. Tal melhora, ainda que insuficiente no caso da $3^{\text {a }}$ série do Ensino Médio deve ser registrada, pois rompe com a tendência percebida até então e pode ser um indicativo de uma tendência crescente no nível de qualidade de ensino e rendimento dos alunos.

Outra característica importante é a revelada pelo resultado do IDEB em termos regionais, tendo em vista que podem ser cruzadas com os índices de analfabetismo e indicarem a presença de um ciclo vicioso. Mais uma vez pode-se apontar na direção da relação entre pobreza de capacidades e pobreza de rendas.

\subsection{Ampliação e equalização do acesso à educação superior}

A abordagem desse tema se justifica devido ao processo histórico iniciado pela chegada tardia do ensino superior no Brasil e por representar uma das paradas finais dentro do ciclo educacional, em outras palavras, a acessibilidade ao ensino superior também indica a qualidade do ciclo de ensino básico. A análise da ampliação e equalização do acesso à educação superior será feita com base na i) evolução das matrículas e no Programa Universidade para Todos - ProUni e ii) desigualdades de acesso à educação superior.

${ }^{121}$ INSTITUTO DE PESQUISA ECONÔMICA APLICADA. Brasil em desenvolvimento: estado, planejamento epolíticaspúblicas. Brasília:IPEA, 2009. Disponívelem: $<$ http://www. ipea.gov.br/portal/index.php?option=com_content \&view=article\&id=239\&Itemid=6>. Acesso em: 12 maio 2010. p. 628. 


\subsubsection{Evolução das matrículas e programa universidade para todos}

Os dados do Censo da Educação Superior de $2007^{122}$ revelaram uma mudança da tendência percebida na década de 1990, em que houve uma forte expansão do setor privado e tímida expansão das matrículas nas instituições públicas de ensino superior. Dois fatores podem explicar tal mudança: i) saturação do modelo de expansão adotado e ii) dinamismo conferido pelo MEC à rede pública federal de ensino superior, a exemplo do Programa de Apoio a Planos de Reestruturação e Expansão das Universidades Federais - Reuni. ${ }^{123}$

O aumento de estudantes nas Instituições Federais de Ensino Superior IFES - foi de 23,4\% e nas Instituições de Ensino Superior privadas foi de 16,5\%. Quanto à oferta de vagas, em relação ao quadriênio anterior, nas IES privadas houve queda de $5 \%$ na taxa de crescimento, antes de $29 \%$, e nas IFES a taxa de crescimento passou de $0,3 \%$ para $25,1 \%$ no período $2004-2007 .{ }^{124}$

O ProUni, no período 2005-2007, viabilizou o crescimento de quase $225 \%$ da concessão de bolsas, "de modo que neste último ano estas bolsas já correspondiam a $8,5 \%$ do total de matrículas nas IES privadas e as novas concessões representavam $61,3 \%$ do acréscimo de matrículas em relação ao ano anterior" ${ }^{125}$

Portanto, ao que cabe ao acesso à educação superior em relação ao número de vagas e viabilização de acesso devido à concessão de bolsas, ou seja, atenuando as desigualdades distributivas, o ProUni tem se revelado um elemento de efetivi-

${ }^{122}$ Divulgação do INEP/MEC.

123 INSTITUTO DE PESQUISA ECONÔMICA APLICADA. Brasil em desenvolvimento: estado, planejamentoepolíticaspúblicas. Brasília:IPEA, 2009. Disponívelem: $<$ http://www. ipea.gov.br/portal/ index.php?option=com_content $\&$ view $=$ article\&id=239\&Itemid=6>. Acesso em: 12 maio 2010. p. 629.

${ }^{124}$ INSTITUTO DE PESQUISA ECONÔMICA APLICADA. Brasil em desenvolvimento: estado, planejamento e políticas públicas. Brasília: IPEA, 2009. Disponível em: <http:// www.ipea.gov.br/portal/index.php?option=com_content\&view=article\&id=239\&Item $\mathrm{id}=6>$. Acesso em: 12 maio 2010. p. 629.

125 INSTITUTO DE PESQUISA ECONÔMICA APLICADA. Brasil em desenvolvimento: estado, planejamento e políticas públicas. Brasília: IPEA, 2009. Disponível em: <http:// www.ipea.gov.br/portal/index.php?option=com_content\&view=article\&id=239\&Item $\mathrm{id}=6>$. Acesso em: 12 maio 2010. p. 630. 
dade do direito à educação. Ressalte-se que existem motivos pelos quais o alunado não alcança a conclusão do ensino médio e que, portanto, o impede de ter acesso ao ensino superior.

\subsubsection{Sobre as desigualdades de acesso à educação superior}

Neste ponto, serão analisadas as taxas de frequência à educação superior a partir das variáveis de renda e raça/cor, tendo em vista que o acesso à educação superior não está restrita ao ingresso, mas revela consistência também em termos de frequência do alunado. Com a implantação do ProUni, a taxa de frequência de pessoas com renda familiar per capita de até 1,5 SM saiu de 45,4\% para 60,6\%, ou seja, aumentou em 15,2\%, e o grupo que se situa entre 1,51 SM e 3 SM acompanhou tal tendência em menor proporção. Portanto, "uma vez que as taxas de crescimento foram maiores na faixa de renda de até 1,5 SM, reduziu-se a diferença entre ambos os grupos de renda, com intensidade ligeiramente maior nos dois primeiros anos de vigência do ProUni." ${ }^{126}$

Em relação à variável cor/raça, a expansão da taxa de frequência entre os brancos foi maior que a dos negros. O maior crescimento entre os negros ocorreu antes da implantação do ProUni - 2002 a 2004, enquanto, entre os brancos, o maior crescimento ocorreu após. Em outras palavras, apesar do crescimento entre os negros ter sido de 54\% nos dois primeiros anos de vigência do programa, em processo de ascensão, tal aumento foi menor que no período de 2002 a 2004, de forma significativa. ${ }^{127}$

${ }^{126}$ INSTITUTO DE PESQUISA ECONÔMICA APLICADA. Brasil em desenvolvimento: estado, planejamento e políticas públicas. Brasília: IPEA, 2009. Disponível em: <http:// www.ipea.gov.br/portal/index.php?option=com_content\&view=article\&id=239\&Item $\mathrm{id}=6>$. Acesso em: 12 maio 2010. p. 631.

127 INSTITUTO DE PESQUISA ECONÔMICA APLICADA. Brasil em desenvolvimento: estado, planejamentoepolíticaspúblicas. Brasília:IPEA, 2009.Disponívelem: $<$ http://www. ipea.gov.br/portal/index.php?option=com_content $\&$ view=article $\&$ id=239\&Itemid $=6>$. Acesso em: 12 maio 2010. p. 631. 
A questão racial é minimizada à medida que aumenta a renda, percebe-se que "na faixa de até $1.5 \mathrm{SM}$, a taxa de frequência de negros correspondia a cerca da metade da registrada pelos brancos, enquanto na faixa de renda subsequente a proporção atingia $83 \%$, em $2007 .{ }^{128}$ Ou seja, a desigualdade ficou situada em $17 \%$, na faixa de renda de 1,51 a 3 SM, enquanto na faixa anterior foi de $50 \%$. Tal fato demonstra que um dos fatores para a diminuição de desigualdades raciais no acesso ao ensino superior é a renda. Contudo, ainda não se pode falar em eliminação das desigualdades.

Ao longo do período 2002-2007, houve a redução das diferenças entre as taxas de frequência à educação superior entre negros e brancos nas duas faixas de renda. ${ }^{129}$ Tal inflexão pode estar associada à insuficiência de oferta de bolsas, bem como à demanda estar perto da saturação, principalmente na faixa de menor renda, em que a diferença é maior. Portanto, "pelo fato de ser pequeno o número de candidatos negros que concluem o ensino médio e que almejam e/ou encontram-se em condições de prosseguir nos estudos em nível superior”. ${ }^{130}$

Interessante notar que a possibilidade do número de candidatos negros ser menor que o de candidatos brancos revela um nó crítico em outro ponto da estrutura educacional. Dessa forma, para que tal desigualdade seja atenuada/eliminada é preciso trabalhar tal questão na educação básica.

Portanto, apesar de ainda persistirem desigualdades no acesso à educação superior, com a implementação do ProUni alguns resultados já são sensíveis, como

${ }^{128}$ INSTITUTO DE PESQUISA ECONÔMICA APLICADA. Brasil em desenvolvimento: estado, planejamentoepolíticaspúblicas. Brasília:IPEA, 2009.Disponívelem: $<$ http://www. ipea.gov.br/portal/ index.php?option=com_content $\&$ view=article\&id=239\&Itemid=6>. Acesso em: 12 maio 2010. p. 632.

129 INSTITUTO DE PESQUISA ECONÔMICA APLICADA. Brasil em desenvolvimento: estado, planejamentoepolíticaspúblicas. Brasília:IPEA,2009.Disponívelem: $<$ http://www. ipea.gov.br/portal/ index.php?option=com_content $\&$ view $=$ article\&id=239\&Itemid=6>. Acesso em: 12 maio 2010. p. 632.

${ }^{130}$ INSTITUTO DE PESQUISA ECONÔMICA APLICADA. Brasil em desenvolvimento: estado, planejamentoepolíticas públicas. Brasília:IPEA, 2009.Disponívelem: $<$ http://www. ipea.gov.br/portal/ index.php?option=com_content $\&$ view=article\&id=239\&Itemid=6>. Acesso em: 12 maio 2010. p. 632. 
a diminuição da desigualdade de acesso entre os estudantes que se situam na faixa de renda de 1,5 SM e na faixa de 1,51 a 3 SM e, ainda, a diminuição na redução das desigualdades de frequência à educação superior associada à renda. Entretanto, persiste a necessidade de viabilizar o acesso em relação aos estudantes negros a partir do fortalecimento de acesso e permanência no ensino básico, e, conforme foi visto nos resultados do Relatório dos ODM, há uma tendência de atenuação da relação entre desigualdades sociais e de acesso à educação.

\section{Conclusão}

Foi possível constatar o aumento do esforço público em implementar políticas educativas para conferir um maior grau de efetividade do art. 205 da CF/88, que dispõe que a educação é um direito de todos. A maior efetividade desse dispositivo demanda a expansão dos serviços educacionais, que, por sua vez, colabora com a geração de capacidades e expansão da liberdade individual, fatores fundamentais para o desenvolvimento de um país, na concepção de desenvolvimento de Amartya Sen. ${ }^{131}$

É salientar que a educação é um dos elementos do "preparo social", ${ }^{132}$ ou seja, que colabora para a formação de uma base social que proporciona sustentação adequada ao êxito econômico. O Estado possui um papel fundamental na expansão educativa, de forma que o gasto é um dos componentes essenciais para tal expansão.

No período de 1995 a 2005, pôde-se constatar que houve expansão da estrutura educacional brasileira a partir da análise da trajetória dos gastos bem como do número de matrículas. Apesar de ser perceptível a oscilação dos gastos, não se

\footnotetext{
${ }^{131}$ Apesar de Sen deixar clara a relação entre pobreza de rendas e pobreza de capacidades, neste artigo a análise foi direcionada para a segunda, tendo em vista que se optou por verificar a efetividade da educação como direito de todos. Em outras palavras, não foi verificado impacto do aumento das capacidades sobre a renda tendo em vista que ultrapassava o objetivo do trabalho.

132 Denominação própria de Amartya Sen (item 1.1)
} 
pode afirmar que haja uma completa instabilidade, tendo em vista que apenas em um dos anos do período analisado houve o decréscimo de gastos em relação ao ano inicial do período, portanto a oscilação observada está restrita a uma faixa específica de gastos. Tal oscilação, ao que consta nos dados, não afetou a trajetória do número de matrículas nas respectivas modalidades de ensino, entretanto, a combinação de tais comportamentos pode ter sérias implicações internas à estrutura de ensino, como por exemplo, a questão da repetência, que poderá ter reflexos na formação do IDEB, caso seja mantido tal comportamento na trajetória dos gastos. Outro meio para verificar as consequências de tal oscilação seria verificar a taxa de frequência do alunado.

$\mathrm{O}$ alto investimento na ampliação da estrutura de ensino permite concluir que existe uma direção comum das preocupações governamentais e a perspectiva de desenvolvimento como liberdade. Como já mencionado, dado o caráter de bem semi-público da educação, esta contribui para o aumento de capacidades, assim como a saúde, e é imprescindível para o aproveitamento, por parte da população, do crescimento econômico de um país.

A formação do preparo social, no entanto, sofre algumas restrições apesar do avanço da estrutura educacional, que pode ser atribuído a outros fatores de desigualdade social, como a desigualdade de renda e diferença de raça/cor. Tais fatores podem ser vistos com nitidez na abordagem dos demais elementos: 1) erradicação do analfabetismo; 2) distorção idade-série; 3) diferenças regionais; 4) nível de qualidade; e 5) acesso à educação superior.

O perfil do analfabetismo demonstra, em síntese, que eles é mais acentuado na população negra, nas regiões menos desenvolvidas, nos segmentos de baixa renda e na população de idade mais avançada. O declínio do analfabetismo está ocorrendo em virtude da escolarização da nova geração ${ }^{133}$ e pelo falecimento dos idosos analfabetos, o que revela que existe uma geração inalcançável pela educação, em outras palavras, uma vez excluídos do sistema educacional, para sempre

${ }^{133}$ Nesse sentido, estão direcionados os esforços para atingir a meta de que todas as crianças concluam o Ensino Fundamental até 2015. 
excluídos. Essa afirmação também é evidenciada quando observada a frequência de adultos e idosos à escola, que revela ser baixa. Dessa forma, apesar de existir um programa destinado à educação de adultos, estes muitas vezes são inalcançáveis pelo sistema de ensino devido à soma de fatores que levam à sua exclusão, como pode ser constatado.

Percebe-se que a conjugação dos fatores de exclusão forma um cinturão de isolamento, que o torna impenetrável pelo sistema educacional, conforme as características visualizadas. Também é perceptível a relação entre pobreza de rendas e pobreza de capacidades, pois a concentração desta última está nos segmentos de baixa renda.

Apesar da expansão do número de matrículas no período analisado, 19952005, percebe-se que a qualidade da educação não obteve níveis satisfatórios, principalmente na $3^{\text {a }}$ série do Ensino Médio. Com o aumento do número de concluintes da educação básica há um tensionamento para entrada no ensino superior, entretanto a ideia de ciclo leva à conclusão de que as falhas ocorridas na educação básica reverberam no ensino superior, em outras palavras, a não atenuação de desigualdades nessa fase ganha proporções na etapa posterior.

No que diz respeito ao acesso à educação superior, é possível notar a redução de desigualdades quanto às variáveis de renda e raça/cor, de forma que houve a redução das desigualdades em razão da condição econômica e étnica do estudante. Entretanto, há indicação de que o maior acesso de negros é obstado frente à inadequada estruturação do ciclo educacional.

Tais fatores combinam para o afunilamento do número de estudantes no ciclo educacional, para reforçar a relação entre pobreza de rendas e de capacidades de uma forma negativa. Destaca-se que a pobreza de rendas, no caso brasileiro, normalmente está associado a outros elementos como raça e localização - regiões Norte e Nordeste, bem como rural.

Para inserir as pessoas que se situam nas faixas de desigualdade social, portanto, não basta a mera expansão da estrutura educacional da forma como foi feita, 
sendo necessárias medidas específicas para atingir a faixa populacional que permanece fora do sistema educativo.

Do exposto, observa-se que a questão da destinação de recursos à educação não é o problema central do Brasil, com exceção à instabilidade relativa apontada. A questão do acesso ao EF também se encontra em boa situação. Os nós críticos estão em outros pontos da estrutura, como a qualidade do ensino, a distorção idade/ série, as desigualdades de renda e a questão do acesso ao ensino superior e, também, a questão do analfabetismo acentuado na faixa etária dos 40 anos ou mais.

Ainda há um longo caminho a ser percorrido para que se possa falar que o direito à educação no Brasil é plenamente efetivo, bem como que a educação pode ser considerada um pilar sólido do desenvolvimento nacional e que há o preparo social para o desenvolvimento do país. As melhoras observadas com a implementação das políticas públicas previstas na $\mathrm{CF} / 88$ em suas sucessivas alterações referentes à educação são significativas e os desafios nacionais são lançados hoje sobre um tecido distinto da década passada.

\section{Aspects of the development and implementation of the right to education in Brazil.}

\section{Abstract}

This article aims to relate aspects of development theory as freedom by Amartya Kumar Sen relevant to education on the effectiveness of the principle laid down in art. 205 of the Constitution, which establish education as a right for everyone. The effectiveness is related to the ability to achieve the purposes for which the standard was created. To measure the effectiveness of art. 205 of CF/88, get up data on the trajectory of public spending on education, enrollment, and eradication of illiteracy, level of education quality and access to higher education, because these are key indicators to measure the output in the area of education. Amartya Sen includes education as one of the factors that contribute to the development of a country. The proposed analysis enables to evaluate the progress and challenges 
ahead of the country's development in education during the post-' 88 . We can point to a significant improvement in the national picture due to the implementation of educational policies in the last decade.

Keywords: Development. Education. Education's policies.

\section{Referências}

BARROS-PLAUTIAU, Ana Flávia; VARELlA, Marcelo Dias. A efetividade do direito internacional ambiental. Brasília: UniCEUB; UNITAR; UnB, 2009.

BRASIL. Ministério da Educação. Primeiros resultados: médias de desempenho do SAEB/2005 em perspectiva comparada. Brasília: INEP, 2007. Disponível em: $<$ http://www.inep.gov.br/download/saeb/2005/SAEB1995_2005.pdf>. Acesso em: 13 mar. 2010.

CASTRO, Cláudio de Moura. Educação brasileira: consertos e remendos. Rio de Janeiro: Rocco, 2007.

CASTRO, Jorge Abrahão de; DUARTE, Bruno de Carvalho. Descentralização da educação pública no Brasil: trajetória dos gastos e das matrículas. Brasília: IPEA, 2008. (Texto para Discussão, n. 1352).

CASTRO, Jorge Abrahão de; RIBEIRO, José Aparecido Carlos (Org.). Situação social brasileira: 2007. Brasília: IPEA, 2009.

EDO, María. Amartya Sen y el desarrollo como libertad: la viabilidad de una alternativa a las estrategias de promoción del desarrollo. Argentina: Universidad Torcuato di Tella, 2002.

FEIJOÓ, Maria del Carmen. Argentina: equidad social y eduación en los '90. Buenos Aires: IIPE -UNESCO, 2002.

IDEB. Nota técnica. Disponível em: <http://www.inep.gov.br/download/Ideb/ Nota_Tecnica_n1_concepcaoIDEB.pdf $>$. Acesso em: 12 maio 2010.

INSTITUTO DE PESQUISA ECONÔMICA APLICADA. Políticas sociais: acompanhamento e análise: 20 anos da Constituição Federal. n. 17. v. 2. Brasília: IPEA, 2009. 
IOSCHPE, Gustavo. A ignorância custa um mundo: o valor da educação no desenvolvimento do Brasil. São Paulo: Francis, 2004.

INSTITUTO DE PESQUISA ECONÔMICA APLICADA. Brasil em desenvolvimento: estado, planejamento e políticas públicas. Brasília: IPEA, 2009. Disponível em:<http://www.ipea.gov.br $>$. Acesso em: 12 maio 2010.

INSTITUTO DE PESQUISA ECONÔMICA APLICADA. Objetivos de desenvolvimento do milênio. Relatório Nacional de acompanhamento. IPEA: Brasília, 2010. Disponível em:<http://www.ipea. gov.br >. Acesso em: 11 maio 2010.

MENEZES, Roberto Goulart; RIBEIRO, Cláudio Oliveira. Políticas públicas pobreza e desigualdade no Brasil: apontamentos a partir do enfoque analítico de Amartya Sen. Disponível em: < http://revistaseletronicas.pucrs.br/ ojs/index. php/ fass/article/view/ 3937/2974 >. Acesso em: 26 maio 2010.

SEN, Amartya Kumar. Desenvolvimento como liberdade. São Paulo: Companhia das Letras, 2000. 